\title{
Structural Origin of High Crack Resistance in Sodium Aluminoborate Glasses
}

\author{
Kacper Januchta ${ }^{1}$, Randall E. Youngman ${ }^{2}$, Ashutosh Goel ${ }^{3}$, Mathieu Bauchy ${ }^{4}$, Sylwester J. Rzoska ${ }^{5}$, Michal \\ Bockowski $^{5}$, Morten M. Smedskjaer ${ }^{1, *}$ \\ ${ }^{1}$ Department of Chemistry and Bioscience, Aalborg University, Aalborg, Denmark \\ ${ }^{2}$ Science and Technology Division, Corning Incorporated, Corning, USA \\ ${ }^{3}$ Department of Materials Science and Engineering, Rutgers, The State University of New Jersey, USA \\ ${ }^{4}$ Department of Civil and Environmental Engineering, University of California, Los Angeles, USA \\ ${ }^{5}$ Institute of High-Pressure Physics, Polish Academy of Sciences, Warsaw, Poland \\ * Corresponding author. e-mail: mos@bio.aau.dk
}

\begin{abstract}
Sodium aluminoborate glasses are found to exhibit favorable mechanical properties, especially high crack resistance, due to their relatively low resistance to network compaction during sharp-contact loading. We here reveal the origin of the high crack resistance by investigating changes in structure and mechanical properties in compositions ranging from peralkaline to peraluminous and by varying the pressure history through an isostatic $\mathrm{N}_{2}$-mediated pressure treatment at elevated temperature. This approach allows us to study the composition dependence of the ease of the glassy network compaction and the accompanying changes in structure and properties, which shed light on the processes occurring during indentation. Through solid state NMR measurements, we show that the network densification involves an increase in the average coordination number of both boron and aluminum and a shortening of the sodium-oxygen bond length. These changes in the short-range order of the glassy networks manifest themselves as an increase in, e.g., density and indentation hardness. We also demonstrate that the glasses most prone to network compaction exhibit the highest damage resistance, but surprisingly the crack resistance scales better with the relative density increase achieved by the hot compression treatment rather than with the extent of densification induced by indentation. This suggests that tuning the network structure may lead to the development of more damage resistant glasses, thus addressing the main drawback of this class of materials.
\end{abstract}

Keywords: glasses, damage resistance, atomic structure, deformation mechanism, indentation. 


\section{Introduction}

Glassy solids offer a range of favorable properties such as transparency, high hardness, relatively lightweight, low-cost raw materials, and in many cases excellent chemical resistance, making them desirable materials for many traditional and novel applications [1]. However, their brittleness, low practical strength, and limited toughness are major drawbacks for future applications, although various post-treatment methods such as thermal [2] and chemical strengthening [3], are being applied to improve the glass mechanics. In addition, significant contributions to improving the mechanical performance through tuning of the chemical composition have been made [4-7], but a fundamental understanding of the composition dependence of crack initiation and growth in glasses is still lacking.

In 1921, Griffith [8] suggested that the low practical strength of oxide glasses is due to surface flaws as stresses concentrate at the tips of the flaws leading to a brittle fracture considering that such glasses do not have a stable shearing mechanism. Sharp-contact loading (i.e., indentation) has subsequently been employed to introduce surface flaws in a controlled manner and to observe the cracking patterns originating from the residual indentation imprint [9-14]. Examination of considerable amounts of indents lead to the observation that different glass systems deform via different mechanisms, which in turn dictates the crack resistance and pattern. Glasses which densify upon indentation tend to form ring cracks around an indent, whereas glasses deforming through volume-conservative shear flow are more likely to form radial/median cracks propagating outwards from the corners of an indent [12]. Later studies quantified the relative contributions of these deformation mechanisms and suggested that the deformation behavior (and thereby the type of cracking) is correlated to the atomic packing density $\left(C_{g}\right)$ and in turn Poisson's ratio $(v)$ [15-18]. However, knowledge of the compositional scaling of the indentation crack resistance $(C R)$ and its relation with other material properties is more limited.

The link between chemical composition and glass network structure, which in turn affects material properties and cracking behavior of a glass, has been thoroughly investigated, especially given the advances in structural characterization techniques, such as solid state nuclear magnetic resonance (NMR) spectroscopy and neutron diffraction. For example, the network of amorphous silica consists of corner-sharing $\mathrm{SiO}_{4}$ tetrahedra $[19,20]$, resulting in a low $C_{g}$ value that favors densification during indentation [15,21]. Addition 
of modifier oxides (e.g., $\mathrm{Na}_{2} \mathrm{O}$ ) to the silicate network tend to fill the interstices with cations and induce the formation of non-bridging oxygens (NBOs), thus hindering densification and facilitating shear flow [22]. These structural changes strongly affect $C R[16,17]$. On the other hand, it has been shown in alkali borate glasses that the resistance to densification is unaffected by the increase in $C_{g}$ upon alkali oxide addition [23]. This demonstrates that further studies are required in order to completely understand the role of chemical composition in governing the deformation and cracking behavior in oxide glasses.

In the search for more damage resistant glass compositions, we here consider a series of sodium aluminoborate glasses, specifically $25 \mathrm{Na}_{2} \mathrm{O}-x \mathrm{Al}_{2} \mathrm{O}_{3}-(75-x) \mathrm{B}_{2} \mathrm{O}_{3}$ with $x$ varying between $5-30 \mathrm{~mol} \%$. The structure of alkali aluminoborate glasses has previously been investigated in Refs. [24-29]. Through magic angle spinning (MAS) NMR studies on ${ }^{11} \mathrm{~B}$ and ${ }^{27} \mathrm{Al}$ nuclei, it has been found that both of the networkforming tetrahedral species tend to compete for the charge-balancing Na-cations. There is a preference towards charge-balancing aluminum tetrahedra $\left(\mathrm{Al}^{\mathrm{IV}}\right)$ rather than boron tetrahedra $\left(\mathrm{B}^{\mathrm{IV}}\right)$. Hence, upon substitution of $\mathrm{Al}_{2} \mathrm{O}_{3}$ for $\mathrm{B}_{2} \mathrm{O}_{3}$, the fraction of four-fold coordinated boron species $\left(N_{4}\right)$ decreases as Nacations are being re-associated to supply the deficient positive charge to $\mathrm{Al}^{\mathrm{IV}}$ units. As the molar content of $\mathrm{Al}_{2} \mathrm{O}_{3}$ exceeds that of $\mathrm{Na}_{2} \mathrm{O}$, five- and six-fold coordinated aluminum species $\left(\mathrm{Al}^{\mathrm{V}}\right.$ and $\mathrm{Al}^{\mathrm{VI}}$ ) are detected. The glasses in this selected system are thus expected to exhibit large differences in boron and aluminum speciation across the series, and also contain low levels of NBOs, given the needs of sodium cations to charge-stabilize boron and aluminum in tetrahedral configuration. The earlier studies did not examine the relation of aluminoborate structure to the mechanical properties, but low NBO content and low $N_{4}$ has previously been found to favor densification during indentation, which in turn should promote high values of $C R[16,17]$. As such, the sodium aluminoborate glasses are an ideal model system for revealing the structural origin of high crack resistance in oxide glasses.

In detail, we here examine the impact of structure on deformation mechanisms and cracking behavior through density, differential scanning calorimetry (DSC), solid state ${ }^{11} \mathrm{~B},{ }^{23} \mathrm{Na}$, and ${ }^{27} \mathrm{Al} \mathrm{NMR}$ spectroscopy, and nano- and micro-indentation measurements. The contributions of densification and shear flow to indentation are determined using atomic force microscopy (AFM). Furthermore, we employ a $\mathrm{N}_{2}$-mediated isostatic compression treatment carried out around the glass transition temperature $\left(T_{g}\right)$ to tune the pressure 
history of the glasses. Compression of glasses at $T_{g}$ is especially useful, since significant permanent volume increase can be obtained on large specimens $\left(\sim \mathrm{cm}^{3}\right)$, thus enabling the evaluation of the change in mechanical properties. Ultimately, insight into the origin of pressure-induced changes in the glassy network may improve the understanding of changes induced by external loading, such as indentation.

\section{Experimental Section}

\subsection{Sample Preparation}

Seven glass compositions in the system $25 \mathrm{Na}_{2} \mathrm{O}-x \mathrm{Al}_{2} \mathrm{O}_{3}-(75-x) \mathrm{B}_{2} \mathrm{O}_{3}$ with $x=5,10,15,20,25,27.5$, and 30 mol \% were prepared, thus covering both peralkaline and peraluminous compositions. To do so, $\mathrm{Na}_{2} \mathrm{CO}_{3}$, $\mathrm{Al}_{2} \mathrm{O}_{3}$, and $\mathrm{H}_{3} \mathrm{BO}_{3}$ powders were first mixed according to the target compositions and these mixtures were melted in Pt-Rh crucibles at $1200-1650{ }^{\circ} \mathrm{C}$ depending on the composition. The melts were quenched onto a steel plate and transferred into an annealing furnace at an estimated glass transition temperature $\left(T_{g}\right)$ using SciGlass database [30]. The chemical compositions were measured using flame emission and inductively coupled plasma spectroscopy methods and results are given in Table 1. The samples are named according to the analyzed compositions (see Table 1).

The $T_{g}$ values were determined from DSC measurements (DSC 449C, Netzsch) as the intercept between the tangent to the inflection point and the extrapolated isobaric heat capacity $\left(C_{p}\right)$ value of the glass for a glass specimen with a known thermal history (i.e., preceded by cooling at $10 \mathrm{~K} / \mathrm{min}$ ). The $C_{p}, T$ curves were acquired after calibrating the DSC output against a similar scan for a sapphire specimen. Glasses were then reannealed for $1 \mathrm{~h}$ at the respective $T_{g}$ value, followed by a cooling in the order of $3 \mathrm{~K} / \mathrm{min}$ achieved by turning off the annealing furnace. The amorphous nature of the glasses was confirmed by means of X-ray diffraction (Empyrean XRD, PANalytical).

All glass compositions were subjected to an isostatic $\mathrm{N}_{2}$-mediated compression treatment at $1.0 \mathrm{GPa}$ at their respective $T_{g}$ value. The permanent compression of the glass samples was achieved by maintaining the high pressure and high temperature conditions for $30 \mathrm{~min}$, and subsequent quenching with an initial 60 $\mathrm{K} / \mathrm{min}$ cooling rate to room temperature. The pressure chamber was then decompressed at a $30 \mathrm{MPa} / \mathrm{min}$ rate. More details regarding the compression treatment setup can be found in Ref. [31]. 


\subsection{Density}

Density values of the as-prepared and compressed glasses were determined using the Archimedes' principle of buoyancy. The weight of each glass specimen (at least $1 \mathrm{~g}$ ) was weighed in air and in ethanol ten times.

\subsection{MAS NMR Spectroscopy}

${ }^{11} \mathrm{~B},{ }^{23} \mathrm{Na}$, and ${ }^{27} \mathrm{Al}$ MAS NMR spectra were acquired with commercial spectrometers (VNMRs, Agilent) and MAS NMR probes (Agilent) for four selected compositions (NAB-5, NAB-15, NAB-24 and NAB-30) and their compressed analogues. The samples were powdered in an agate mortar, packed into $3.2 \mathrm{~mm}$ zirconia rotors, and spun at $20 \mathrm{kHz}$ for ${ }^{11} \mathrm{~B}$ MAS NMR and $22 \mathrm{kHz}$ for both ${ }^{27} \mathrm{Al}$ and ${ }^{23} \mathrm{Na}$ MAS NMR experiments. ${ }^{27} \mathrm{Al}$ and ${ }^{23} \mathrm{Na}$ MAS NMR data were collected at $16.4 \mathrm{~T}$ (182.34 and 185.10 MHz resonance frequencies, respectively), using a $0.6 \mu$ s $(\sim \pi / 12$ tip angle) pulse width for uniform excitation of the resonances. A range of 400 to 1000 acquisitions were co-added and the recycle delay between scans was 2 s. ${ }^{11}$ B MAS NMR experiments were conducted at $11.7 \mathrm{~T}(160.34 \mathrm{MHz}$ resonance frequency), incorporating a $4 \mathrm{~s}$ recycle delay, short rf pulses $(0.6 \mu \mathrm{s})$ corresponding to a $\pi / 12$ tip angle, and signal averaging of 400 to 1000 scans. The acquired spectra were processed with minimal apodization and then referenced to aqueous boric acid (19.6 $\mathrm{ppm})$, aqueous $\mathrm{NaCl}(0 \mathrm{ppm})$, and aqueous aluminum nitrate $(0 \mathrm{ppm})$. Fitting of the MAS NMR spectra was performed using DMFit [32] and the CzSimple model, accounting for distributions in the quadrupolar coupling constant, was utilized for ${ }^{27} \mathrm{Al}$ and ${ }^{23} \mathrm{Na}$ MAS NMR spectra. The "Q MAS 1/2" and Gaus/Lor functions were used to fit 3 - and 4-fold coordinated boron resonances in the ${ }^{11} \mathrm{~B}$ MAS NMR data, respectively, and $N_{4}$ was calculated from the relative areas of these peaks, with a small correction due to the overlapping satellite transition of the 4-fold coordinated boron peak [33].

\subsection{Indentation}

Indentation analyses were performed on both as-prepared and compressed glasses. Prior to indentation, appropriate specimens (thickness $>2 \mathrm{~mm}$, area $\approx 2-3 \mathrm{~cm}^{2}$ ) were cut and polished. The first steps of grinding and polishing were done in water using $\mathrm{SiC}$ adhesive discs, but the final steps were done using water-free diamond suspensions to avoid surface hydration. Microindentation analysis was performed using a Duramin 
5 microindenter (Struers) equipped with a Vickers geometry diamond tip. At least 30 symmetrical indents were produced at 8 different loads ranging from $245 \mathrm{mN}$ to $19.6 \mathrm{~N}$ with loading time of $10 \mathrm{~s}$ for each specimen. The resulting indents were evaluated using optical microscopy. The length of the resulting indent impression diagonals, as well as the number and the length of the cracks emerging from the corners of the indent, were recorded $\sim 1 \mathrm{~min}$ after unloading. The indentation measurements were performed at ambient temperature with relative humidity of $47 \pm 5 \%$.

To determine the indentation deformation mechanisms, the topography of at least 10 indents produced at $245 \mathrm{mN}$ were evaluated using AFM (Ntegra, NT-MDT) before and after a thermal annealing treatment at $0.9 T_{g}$ (in K) for 2 hours. As these measurements are very time consuming, only selected as-prepared samples were analyzed. This AFM-annealing method, suggested in Ref. [15], enables the quantification of the densification and isochoric shear-flow contributions to the total volume of the indent, as the thermal treatment is sufficient to recover the compacted matter, while the viscosity is sufficiently high to avoid viscous flow. Silicon tip cantilevers (NSG10, NT-MDT) were used in semi-contact mode with a scanning frequency of $0.5 \mathrm{~Hz}$ to create $20 \times 20 \mu \mathrm{m}^{2}$ images with a resolution of $256 \times 256$ pixels.

Nanoindentation was performed using a Nano Indenter XP (MTS) equipped with a Berkovich geometry tip. At least 12 loading-unloading cycles were repeated for each specimen of thickness larger than $2 \mathrm{~mm}$. The applied load and the displacement were continuously measured during loading, hold, and unloading segments of the measurement. The target displacement was $2000 \mathrm{~nm}$ in each case. The mechanical properties acquired from nanoindentation experiments, i.e., nano-hardness $\left(H_{\text {nano }}\right)$ and reduced modulus $\left(E_{r}\right)$, were calculated according to the Oliver-Pharr methodology [34].

\section{Results and Discussion}

\subsection{Short-Range Order Glass Structure}

${ }^{11} \mathrm{~B}$ and ${ }^{27} \mathrm{Al}$ MAS NMR spectra are shown in Figures $1 \mathrm{a}$ and $1 \mathrm{~b}$, respectively, for the four selected glass compositions. Significant variations in the chemical environment of the network-forming species are found as a function of both chemical composition and pressure history. The fraction of $\mathrm{B}^{\mathrm{IV}}$ units decreases with increasing $\mathrm{Al}_{2} \mathrm{O}_{3}$ content, as these structures are consumed at the expense of formation of $\mathrm{Al}^{\mathrm{IV}}$ due to the 
preference for sodium to charge-stabilize $\mathrm{Al}^{\mathrm{IV}}$. This composition dependence of boron speciation is in agreement with literature results for sodium aluminoborate glasses $[24,25,28,29]$. The composition-induced changes in aluminum speciation are more subtle as $\mathrm{Al}^{\mathrm{IV}}$ units are the predominant structural species in all asprepared glasses. However, a minor fraction of five-coordinated aluminum species is found, especially in the peraluminous glasses (Table 2). This change in aluminum environment is due to the fact that there is no longer a sufficient amount of Na-cations to charge balance $\mathrm{Al}^{\mathrm{IV}}$ units, once the molar content of $\mathrm{Al}_{2} \mathrm{O}_{3}$ exceeds that of $\mathrm{Na}_{2} \mathrm{O}$. The compositional dependence of the relative fraction of each aluminum and boron network-forming unit is illustrated in Figure 2. As expected, the major effect of $\mathrm{Al}_{2} \mathrm{O}_{3}$-for- $\mathrm{B}_{2} \mathrm{O}_{3}$ substitution is the formation of $\mathrm{Al}^{\mathrm{IV}}$ units at the expense of $\mathrm{B}^{\mathrm{IV}}$ units with an approximate one-to-one exchange rate, i.e., one mole of $\mathrm{Na}$ cations become associated with one mole of $\mathrm{Al}^{\mathrm{IV}}$ sites upon withdrawal of one mole of $\mathrm{B}^{\mathrm{IV}}$ sites. It is noteworthy that the rate of $\mathrm{B}^{\mathrm{IV}}$-to- $\mathrm{Al}^{\mathrm{IV}}$ conversion is slower in the peraluminous regime compared to that in the peralkaline regime. On the other hand, the relative fraction of trigonal boron units $\left(\mathrm{B}^{\mathrm{III}}\right)$ exhibits a significant decrease in the peraluminous region with increasing $\left[\mathrm{Al}_{2} \mathrm{O}_{3}\right]$, while there is a sudden increase in the fraction of higher coordinated aluminum species (i.e., $\mathrm{Al}^{\mathrm{V}}$ and $\mathrm{Al}^{\mathrm{VI}}$ ) (Figure 2). The average coordination number for the network-forming cations, which can be calculated based on the distribution of $\mathrm{B}$ and $\mathrm{Al}$ species, appears to increase in the order NAB-5 (3.37) < NAB-15 (3.37) < NAB-24 (3.39) < NAB-30 (3.44). We can thus infer that the connectivity of the aluminoborate network is approximately constant in the peralkaline region and then increases upon crossing the peralkaline/peraluminous border.

Upon compression, the relative intensity of the $\mathrm{B}^{\mathrm{IV}}$ band in the ${ }^{11} \mathrm{~B}$ MAS NMR spectra increases for all investigated glasses (Figure 1a), i.e., the average coordination number of boron increases with respect to the values in the as-prepared glasses. The aluminum speciation is subject to a similar change, i.e., an increase in the relative intensities of $\mathrm{Al}^{\mathrm{V}}$ and $\mathrm{Al}^{\mathrm{VI}}$ (Figure 1b). Similar pressure-induced changes in the coordination number of network-forming cations have previously been recorded for different oxide glass systems [35-40]. The MAS NMR spectra also show that the high- $\mathrm{Al}_{2} \mathrm{O}_{3}$ glasses exhibit the largest pressure-induced structural changes. This is also clear from Figure 2, as it is seen that differences in fractions of the network formers in as-prepared and compressed samples are more pronounced in the peraluminous region. The finding is in agreement with the fact that the $\mathrm{Al}_{2} \mathrm{O}_{3}$-rich glasses display larger plastic compressibility (Table 1), which 
here describes the ability of the glass to permanently change volume upon the pressure treatment [31]. In other words, the glasses with the lowest resistance to compaction at $T_{g}$ exhibit the largest short-range order structural rearrangements.

${ }^{23} \mathrm{Na}$ MAS NMR spectra of the aluminoborate glasses present additional insight into the compositional dependence of short-range order structure (Figure 3a). However, these spectra are significantly less affected by the changes in chemical composition and pressure history compared with the ${ }^{11} \mathrm{~B}$ and ${ }^{27} \mathrm{Al}$ MAS NMR spectra. Nevertheless, we observe systematic shifts in the ${ }^{23} \mathrm{Na}$ peak position as a result of both $\mathrm{Al}_{2} \mathrm{O}_{3}$-for$\mathrm{B}_{2} \mathrm{O}_{3}$ substitution and pressure treatment (Figure $3 \mathrm{~b}$ ). We note that the fitting of ${ }^{23} \mathrm{Na}$ MAS NMR spectra is prone to error due to the difficulty of separating quadrupolar effects from other effects, but we expect that both compositional and pressure-induced trends in these data are meaningful. The ${ }^{23} \mathrm{Na}$ chemical shift has previously been associated with the $\mathrm{Na}$ coordination number and $\mathrm{Na}-\mathrm{O}$ bond length in both crystalline and amorphous materials $[41,42]$, with an increase in chemical shift corresponding to a decrease in the Na-O bond length. In this study, we obtain the isotropic chemical shift for ${ }^{23} \mathrm{Na}$ by fitting the high field MAS NMR spectra as described in Section 2.3. In this manner, the true chemical shift is isolated from contributions of the quadrupolar coupling constant and both parameters are then studied as a function of both glass composition and compression. The latter does not change significantly with pressure, so overall the changes in ${ }^{23} \mathrm{Na}$ MAS NMR spectra in Figure 3a are due mainly to changes in chemical shift. We observe pronounced increases in the ${ }^{23} \mathrm{Na}$ chemical shift with pressure, with the exception of the NAB-30 glass that is peraluminous (Figure 3b). Such increases in ${ }^{23} \mathrm{Na}$ shielding, due to shortening of the average Na-O bond distance, occur upon both $\mathrm{Al}_{2} \mathrm{O}_{3}$-for- $\mathrm{B}_{2} \mathrm{O}_{3}$ substitution and isostatic compression, although these two alterations of the glassy network characteristics have opposite impact on the packing density of the glasses. That is, the hot compression leads to a more efficiently packed network, whereas the addition of $\mathrm{Al}_{2} \mathrm{O}_{3}$ results in a decrease in atomic packing density (Table 1). Pressure-induced shortening of the Na-O bond has previously been reported [37,43], whereas there is no available literature data on the effect of $\mathrm{Al}_{2} \mathrm{O}_{3}-$ for- $-\mathrm{B}_{2} \mathrm{O}_{3}$ substitution on the sodium environment to the authors' knowledge. The composition dependence of the ${ }^{23} \mathrm{Na}$ chemical shift may be understood in terms of the difference in electronegativity of boron and aluminum. The electron density is shifted more towards the oxygen anion in an Al-O bond compared to the case of B-O 
bond, resulting in a higher partial negative charge on the oxygens in an $\mathrm{Al}^{\mathrm{IV}}$ unit. These oxygens are therefore more adequate to be charge-balanced by the Na-cation than the oxygens in a $\mathrm{B}^{\mathrm{IV}}$ unit, leading to a shortened Na-O distance in $\mathrm{Al}_{2} \mathrm{O}_{3}$-rich glasses. Furthermore, this may be interpreted as an explanation for the charge-balancing preference of $\mathrm{Na}$ towards $\mathrm{Al}^{\mathrm{IV}}$ sites.

In the case of the as-prepared and compressed NAB-30 glasses, where $\mathrm{Al}_{2} \mathrm{O}_{3}$ is in excess of $\mathrm{Na}_{2} \mathrm{O}$, the impact of pressure does not lead to a shortening of the average Na-O distance, but in fact the ${ }^{23} \mathrm{Na}$ chemical shift decreases slightly (Fig. 3b). Within the error of the fitting results for these MAS NMR spectra, the average sodium environment in this composition is not sensitive to compression, at least under the conditions used in this study. The slight change in MAS NMR peak position for this glass resembles the other compositions studied here, i.e., a pressure-induced increase in ${ }^{23} \mathrm{Na}$ MAS NMR shift (Fig. 3a). However, fitting of the spectra shows that the apparent change in MAS NMR shift, with no significant change in isotropic chemical shift, is therefore due to a change in the quadrupolar coupling constant for ${ }^{23} \mathrm{Na}$, which may result from a subtle change in the sodium coordination number. Since average Na-O distance appears to be invariant with pressure, the densification mechanisms appear to differ to some extent from the other glasses.

\subsection{Glass Transition and Density}

The substitution of alumina for boron oxide in the sodium aluminoborate glass series initially decreases the value of $T_{g}$, but $T_{g}$ increases again when the molar content of $\mathrm{Al}_{2} \mathrm{O}_{3}$ exceeds that of $\mathrm{Na}_{2} \mathrm{O}$ (Figure 4). Hence, there is a pronounced minimum in the compositional scaling of $T_{g}$ around the metaluminous composition. This trend is in agreement with previously reported $T_{g}$ data available for this system [25], and with the structural changes in the aluminoborate network induced by the $\mathrm{Al}_{2} \mathrm{O}_{3}$-for- $\mathrm{B}_{2} \mathrm{O}_{3}$ substitution, which were discussed in the section above and supported by Refs. [24,25,28,29]. In binary alkali borate glasses at 25 mol\% alkali oxide, all available alkali cations supply positive charge to the negatively charged $\mathrm{B}^{\mathrm{IV}}$ units[44]. In the aluminoborate system, the substitution of the network-forming species leads to formation of $\mathrm{Al}^{\mathrm{IV}}$ at the expense of $\mathrm{B}^{\mathrm{IV}}$ achieved by re-association of the Na-cations. Hence, the average coordination number and thus the overall network connectivity [45] remains constant in the peralkaline region. This is in contrast to, 
e.g., alkali aluminosilicate glasses, which exhibit an increase in $T_{g}$ upon $\mathrm{Al}_{2} \mathrm{O}_{3}$-for- $\mathrm{SiO}_{2}$ substitution due to the consumption of NBOs and formation of rigid tetrahedra $[40,46]$. Hence, the observed decrease in $T_{g}$ with increasing $\left[\mathrm{Al}_{2} \mathrm{O}_{3}\right]$ in the peralkaline region for the sodium aluminoborate glasses cannot be justified by the change in network connectivity. It also cannot be assigned to the difference in the bond strength of B-O and Al-O, since $\mathrm{Al}_{2} \mathrm{O}_{3}$ has a higher dissociation energy than $\mathrm{B}_{2} \mathrm{O}_{3}$ [47]. Additional work is therefore required to understand the composition dependence of $T_{\mathrm{g}}$ in the peralkaline region. In the peraluminous region, the excess $\mathrm{Al}_{2} \mathrm{O}_{3}$, which is not charge-balanced in tetrahedral configuration by Na-cations, exists in five- and six-coordinated species and possibly also causes formation of oxygen triclusters (i.e., oxygen anions coordinated with three network-forming cations) $[24,26,27,29]$. In either case, the glassy network becomes more rigid, which can explain the sudden increase in $T_{g}$.

The composition dependence of the room-temperature density $(\rho)$ is shown in Figure 5a. Similar to the trend in $T_{g}$, density initially decreases and then increases with increasing $\mathrm{Al}_{2} \mathrm{O}_{3}$ content, although the local minimum is less pronounced and shifted more towards the peralkaline regime. This behavior is assigned to two competing effects when substituting $\mathrm{Al}_{2} \mathrm{O}_{3}$ for $\mathrm{B}_{2} \mathrm{O}_{3}$. That is, increasing molar mass of the glass $\left(\mathrm{Al}_{2} \mathrm{O}_{3}\right.$ is heavier than $\mathrm{B}_{2} \mathrm{O}_{3}$ ) and decreasing packing efficiency of the glassy network. The latter can be seen by calculating the atomic packing density $\left(C_{\mathrm{g}}\right)$, which is the ratio between the lowest theoretical value of volume occupied by the constituent atoms and the molar volume of the glass. The coordination numbers for $\mathrm{Na}$ and $\mathrm{O}$ are assumed to be six and two, respectively, while those for $\mathrm{Al}$ and $\mathrm{B}$ are determined from MAS NMR results (Table 2). Ionic radii are taken from Ref. [48]. As shown in Table $1, C_{\mathrm{g}}$ initially decreases with increasing $\left[\mathrm{Al}_{2} \mathrm{O}_{3}\right]$ before reaching an apparent plateau when approaching the peraluminous regime.

The compositional scaling of density for the compressed glasses resembles that of the as-prepared glasses, but the absolute values have increased significantly upon compression (Figure 5a). The degree of densification is quantified by calculating the plastic compressibility $(\beta)$ similarly to Ref. [31],

$$
\beta=\frac{\rho_{f}-\rho_{i}}{\rho_{i} \cdot P},
$$

where subscripts $f$ and $i$ represent the final and initial density values, respectively, and $P$ is the applied isostatic pressure in GPa. As shown in Figure 5b, the $\mathrm{Al}_{2} \mathrm{O}_{3}$-rich glasses exhibit significantly larger $\beta$ values. However, although $\beta$ displays an initial increase in the peralkaline region with $\left[\mathrm{Al}_{2} \mathrm{O}_{3}\right]$, it exhibits an 
approximate constant value around the metaluminous composition. By considering the structural pressure response of the NAB-24 and NAB-30 glasses, we note that the chemical environment of $\mathrm{Na}$ is most sensitive to compression in the peralkaline glasses (Fig. 3b), whereas the chemical environments of $\mathrm{Al}$ and $\mathrm{B}$ are most sensitive in the peraluminous glasses (Fig. 2). However, the resulting $\beta$ values are practically equal for the NAB-24 and NAB-30 glasses, i.e., different densification mechanisms are in play when the different glasses are subjected to hot compression.

The compositional scaling of $\beta$ may also be interpreted in terms of the trend in atomic packing density (see inset of Figure 5b). The $\mathrm{B}_{2} \mathrm{O}_{3}$-rich glasses are the most densely packed, i.e., there is more open space available for compaction in the $\mathrm{Al}_{2} \mathrm{O}_{3}$-rich glasses. However, this correlation between $\beta$ and $C_{\mathrm{g}}$ does not always hold, as amorphous silica has a relatively open structure [21], but its plastic compressibility is significantly lower than of the aluminoborate glasses (unpublished data). That is, densification of silica (e.g., changing $\mathrm{Si}-\mathrm{O}-\mathrm{Si}$ angle and increasing $\mathrm{Si}$ coordination number) is associated with a larger energy penalty than that of sodium aluminoborate (e.g., changing Na-O distance or increasing $\mathrm{B}$ coordination number). This implies that the ease of compaction at $T_{g}$ is not only controlled by the openness of the structure, but also by the ability of the network to reorganize, which in turn is related to its rigidity. Nevertheless, within a family of glasses, the correlation between $\beta$ and $C_{\mathrm{g}}$ may hold, since the differences in network rigidity and densification mechanism are expected to be relatively small.

\subsection{Elasticity and Hardness}

Nanoindentation experiments on the as-prepared and compressed aluminoborate glasses provide insight into the resistance to elastic and elastoplastic deformation quantified by the reduced modulus $\left(E_{r}\right)$ and hardness $\left(H_{\text {nano }}\right)$, respectively. The load-displacement curves for all investigated glasses are shown in Figure $\mathrm{S} 1$ in the Supplementary Material. The results are shown in Figures $6 \mathrm{a}$ and $6 \mathrm{~b}$, respectively. $E_{r}$ data offers the possibility to obtain an approximation of Young's modulus $(E)$ values, but the lack of Poisson's ratio data and the formation of material pile-up around the edges of indent makes it impossible to determine $E$ accurately using this method [49]. Hence, these results will be used only for internal comparison. The trends in both $E_{r}$ and $H_{\text {nano }}$ resemble that of $T_{g}$ (Figure 4), although more scatter is recorded for $E_{r}$ and $H_{\text {nano }}$ and the 
local minima are less pronounced. In the peralkaline region, where there is no significant difference in connectivity of the network across the compositions, $E_{r}$ and $H_{\text {nano }}$ decrease slightly with $\left[\mathrm{Al}_{2} \mathrm{O}_{3}\right]$, which is presumably due to the decrease in packing density (Table 1). In other words, there are fewer bonds per unit of volume to be strained or broken during loading, thus decreasing the resistance to deformation. In the peraluminous region, the average coordination number of the network-forming species increases, resulting in a more rigid network, manifesting itself as an increase in $E_{r}$ and $H_{\text {nano. }}$.

The pressure treatment causes an increase in both $E_{r}$ and $H_{\text {nano }}$. These observations are supported by those previously reported in Refs. [38,50,51], and are presumably partially a consequence of i) an increasing packing efficiency and ii) an increasing connectivity of the glassy network. Hence, there is a larger number of bonds both per unit of volume and per atom in the compressed glasses, which explains the increased resistance to deformation. It is noteworthy that the relative pressure-induced increases in $E_{r}$ and $H_{\text {nano }}$ are similar to each other (approximately 30\% increase following hot compression at $1 \mathrm{GPa}$ ). This behavior has interesting implications for the elastoplastic ratio defined as the ratio between Young's modulus (elastic deformation resistance) and hardness (resistance to elastoplastic deformation), which is correlated with the extent of elastic recovery during indentation [18,52]. Materials deforming predominantly plastically (e.g., soft metals) have high elastoplastic ratio values, whereas materials with large elastic contribution to the deformation (e.g., rubber) have low elastoplastic ratio values. Furthermore, the elastoplastic ratio is used in calculations of indentation fracture toughness in brittle materials [53] and of stresses driving indentation cracking [17,54]. For the investigated series of sodium aluminoborate glasses, the elastoplastic ratio (here expressed as $E_{r} / H_{\text {nano }}$ in lack of Poisson's ratio measurements necessary to calculate $E$ ) is thus unaffected by the compression treatment, i.e., the as-prepared and compressed glasses display similar elastic recovery during indenter unloading. This is an important observation with respect to understanding the indentation cracking behavior of these glasses (see below). It is important to note that this argument assumes that Poisson's ratio does not vary significantly with pressure, since $E_{r} / H_{\text {nano }}$ and $E / H$ are then expected to exhibit similar pressure dependence. Considering a wide range of different oxide glasses [55], Poisson's ratio is found to only vary by up to 0.014 upon hot compression at $1 \mathrm{GPa}$, i.e., its effect on $E$ is negligible. However, 
the change in packing density may lead to an enhanced pile-up deformation [51], affecting the correct evaluation of $E_{r}$ [49].

The hardness of the glasses has also been quantified through microindentation using a Vickers type pyramid. Figure 7 shows the compositional dependence of Vickers hardness $\left(H_{V}\right)$ measured at $0.98 \mathrm{~N}$, showing the same trends for both as-prepared and compressed series as that of $H_{\text {nano }}$. The absolute values differ primarily due to the different methods of hardness calculation, as $H_{\text {nano }}$ considers the projected indent surface area, whereas $H_{V}$ considers surface contact area of the indenter. In addition, the indentation size effect [56] and the difference in indenter tip geometry [57] may affect the hardness. $H_{V}$ values recorded at different loads are shown in Figures S2 and S3 in the Supplementary Material for all investigated glasses.

The relative pressure-induced increase in $H_{V}\left(\Delta H_{V} /\left(H_{V, i} P\right)\right)$ displays a similar compositional dependence as plastic compressibility (Figure 7b). In a recent study, a good correlation between the relative pressure-induced increase in elastic moduli and plastic compressibility was reported [55]. Our results indicate that the extent of network compaction achieved through isostatic compression treatment at $T_{g}$ also scales well with the increase in hardness.

\subsection{Indentation Cracking Behavior}

In addition to the determination of $H_{V}$, microindentation offers the possibility to examine the cracking behavior of the glasses. In general, the as-prepared glasses exhibit larger resistance to radial/median crack initiation compared to the compressed glasses, in agreement with previously reported data $[38,40,51]$. The load, composition, and pressure history dependence of the indentation cracking behavior is illustrated in Figures 8 and 9 for a subset of the as-prepared and compressed samples, respectively. We note that for some glasses, the highest applicable load of the indentation apparatus $(19.6 \mathrm{~N})$ is insufficient to induce radial/median cracking. Such high threshold for crack initiation has rarely been recorded in the literature $[4,7,58,59]$ for as-prepared oxide glasses.

The impact of pressure treatment on the crack initiation resistance is clearly evident from a qualitative inspection of the indent images, whereas the composition dependence of the cracking behavior is more subtle and needs quantification in order to distinguish trends across the series. To do so, the crack probability 
curves for all glasses are shown in Figures 10a and 10b for as-prepared and compressed glasses, respectively. Here, crack probability at a given load is defined as the number of median/radial cracks emanating from the four corners of the Vickers indent impression. In other words, an average of two cracks per indent corresponds to a crack probability of $50 \%$, which is denoted as the crack resistance $(C R)$. As noted above, the highest experimental load $(19.6 \mathrm{~N})$ is insufficient to induce $50 \%$ cracking for some of the as-prepared glasses (Figure 10a), prohibiting accurate determination of $C R$. For these glasses, the $C R$ values were estimated by extrapolating the trend in cracking probability, i.e., these results should be treated with caution. Nevertheless, it can be concluded that there is a convincing composition dependence of $C R$ for both asprepared and compressed glasses (Figure 11a), with the $\mathrm{Al}_{2} \mathrm{O}_{3}$-rich glasses exhibiting the highest $C R$ values. The consequence of the pressure treatment is that $C R$ decreases for all investigated compositions, which is also evident from the indent impression images (Figures 8 and 9). Furthermore, a discontinuity in the compositional dependence of $C R$ is observed between NAB-24 and NAB-28 glasses, indicating that some structural changes controlling cracking behavior may occur upon crossing the peralkaline/peraluminous border.

Similar conclusions can be drawn for the ratio between the length of a radial/median crack $(c)$ and the indent half-diagonal $(a)$. This quantity is a measure of glass brittleness, as it describes the relative sizes of the fracture and deformation zones [14]. $c / a$ appears to decrease with increasing $\mathrm{Al}_{2} \mathrm{O}_{3}$ content (Figure 11b). On the other hand, the glasses become more brittle (c/a increases) upon compression, supporting previous findings $[38,40,51]$ and the recorded trends in $C R$ (Figure 11a). The compositional dependences of $c / a$ for the as-prepared and compressed glasses are parallel. To summarize the indentation cracking behavior, $\mathrm{Al}_{2} \mathrm{O}_{3^{-}}$ rich glasses exhibit more favorable cracking properties (i.e., low $c / a$ and high $C R$ ) than $\mathrm{B}_{2} \mathrm{O}_{3}$-rich glasses. This is true even after compression despite the fact that these glasses have undergone the largest extent of pre-densification prior to indentation (Figure 5b). In other words, the cracking behavior is strongly affected by the local chemical environment in the glasses.

As mentioned above, nanoindentation provides insight into the composition and pressure dependence of the elastoplastic ratio as the displacement and applied load during an indentation cycle can be measured. Considering that the elastoplastic ratio is needed for calculating the indentation fracture toughness [53] as 
well as the driving forces for indentation cracking [17,54], $E_{r} / H_{\text {nano }}$ is expected to affect $c / a$ and $C R$ of the glasses. However, we observe a pressure-induced increase in $c / a$ and decrease in $C R$, with no significant change in $E_{r} / H_{\text {nano }}$. In other words, the cracking behavior of the investigated sodium aluminoborate glasses is influenced by the pressure treatment, but apparently not through a change in the extent of elastic recovery. The results of a previous study [51] suggest that the increase in $C R$ is due to the decrease in volume recovery ratio $\left(V_{R}\right)$, i.e., a compressed glass exhibits an increased resistance to densification during indentation, leading to a larger extent of shear flow deformation resulting in larger residual stress around the indentation zone, which promotes crack initiation.

\subsection{Origin of High Crack Resistance}

In contrast to density, $T_{g}, E_{r}, H_{\text {nano }}$ and $H_{V}$, there is no abrupt change in the composition dependence of the crack-related properties ( $c / a$ and $C R$ ) around the peralkaline/peraluminous border (Figures 11a and 11b). This indicates that the network connectivity is not the only parameter controlling indentation cracking, since aluminum and boron speciations are changing non-monotonically at the peralkaline/peraluminous border (Figure 2). The origin of the favorable cracking behavior of the sodium aluminoborate glasses might therefore be related to the ability of the glasses to undergo densification during indenter loading. To do so, we apply the method by Yoshida et al. [15] to quantify the densification and shear-flow contributions to the total indent volume. This method considers the topography of an indent before and after a sub- $T_{g}$ annealing. An example of a typical set of AFM-images is shown in Figure 12a. Since there is little difference across the compositions, the AFM-images recorded for the remaining glass compositions are shown in Figure S4 in the Supplementary Material. The densified volume is contained within a roughly hemispherical area beneath the indenter [12] and can be recovered by thermal treatment $[10,15]$. The ratio between the recoverable volume and the total indent volume can be calculated as

$$
V_{R}=\frac{\left(V_{i}^{-}-V_{a}^{-}\right)+\left(V_{a}^{+}-V_{i}^{+}\right)}{V_{i}^{-}}
$$

where $V_{R}$ is the volume recovery ratio, $V$ is volume, the subscripts $i$ and $a$ refer to initial and annealed volumes, respectively, and the superscripts - and + refer to the volume contributions below and above the surface of the glass, respectively. Furthermore, Sellapan et al. [17] suggested an additional distinction of the 
shear-flow displaced volume, as the part of the volume resulting in pile-up at the edges of an indent is not assumed to lead to residual stress. The pile-up volume fraction $\left(V_{P}\right)$ is determined as

$$
V_{P}=\frac{\left(2 V_{i}^{+}-V_{a}^{+}\right)}{V_{i}^{-}}
$$

We here consider a subset of the as-prepared glasses, which are subjected to AFM investigations. The composition dependence of the calculated values of $V_{R}$ and $V_{P}$ are presented in Figure 12b. A steady increase in $V_{R}$ with increasing $\mathrm{Al}_{2} \mathrm{O}_{3}$ content is observed in the peralkaline region, followed by a more sudden decrease in the peraluminous region. This significant difference between the $V_{R}$ values of NAB-24 and NAB30 glasses could be related to the different densification mechanisms activated during hot compression, as shown in MAS NMR studies. The $V_{P}$ values are generally small, with the $\mathrm{B}_{2} \mathrm{O}_{3}$-rich glasses being most prone to form pile-up upon indentation, in agreement with the compositional dependence of packing density (Table 1) [17]. On the other hand, all the glasses exhibit relatively large densification contributions to the indent volume compared with existing literature data for other oxide glasses [15-18,23,51,58-63], as shown in Figure 13. This low resistance to densification (i.e., large $V_{R}$ ) of the sodium aluminoborate glasses may be related to the ease of structural rearrangement, e.g., achieved through an increase in coordination number of the network-forming boron and aluminum species under an applied load/pressure. Kato et al. showed that borate-containing glasses with lower fractions of boron tetrahedra (i.e., lower $N_{4}$ ) undergo larger extent of densification, resulting in larger $C R[16,58]$. The correlation between $N_{4}$ and $C R$ holds for the studied sodium aluminoborate system with the most $\mathrm{B}_{2} \mathrm{O}_{3}$-rich glasses displaying the lowest resistance to radial/median cracking (Figure 11b). However, the correlation between $V_{R}$ and $C R$ is poorly supported in this study across the entire range of studied compositions. Indeed, both $V_{R}$ and $C R$ initially increase with increasing $\left[\mathrm{Al}_{2} \mathrm{O}_{3}\right]$, but $V_{R}$ exhibits a local maximum around the peralkaline/peraluminous border (Figure 12b), which leads to a poor scaling with the recorded trend in $C R$ (Figure 14). This might due to a different stress dissipation mechanism in the peraluminous glasses, but additional work is required to fully understand the role of chemical composition on indentation cracking and deformation mechanisms. In conclusion, the relatively high extent of densification during sharp-contact loading may be a plausible explanation for the generally high $C R$ values of this system compared to other families of glasses, but $V_{R}$ fails to account for the complete compositional dependence of $C R$. 
A stronger correlation is found between $C R$ and plastic compressibility (Figure 14), although at first it appears less intuitive, since $\beta$ describes the ease of permanent densification at elevated temperature, where viscous flow of the glassy network plays a dominant role [39], while $V_{R}$ is the glass' ability to undergo densification at room temperature, i.e., under the same conditions as those used for examination of cracking behavior. It should be stressed that for the damage-resilient glasses studied herein, the applied loads used during the AFM analysis and $C R$ determination differ by more than an order of magnitude. The distribution between densification and shear flow volumes and thus also the level of residual stress driving indentation cracking is not necessarily constant as a function of load due to the indentation size effect, although this assumption is often found in literature $[15,17,18]$. Hence, it would be desirable in future work to investigate the indentation deformation mechanisms at higher loads to confirm this assumption and examine the extent of densification occurring at loads leading to crack initiation, although inspection of indents produced at much higher loads is time-consuming. On the other hand, hot compression treatment employed in this study proves to be a valuable substitute for the purpose of investigating the correlation between $C R$ and network deformation mechanisms. Indeed, the result of Figure 14 implies that for the sodium aluminoborate system studied here, $C R$ is controlled to a large extent by $\beta$. Studying glass compositions with intermediate $\beta$ values would be desirable in order to confirm the dependence of $C R$ on $\beta$. Nevertheless, this apparent relation may be valid assuming that the structural rearrangements occurring during indentation at high load are related to those occurring at elevated pressure/temperature. Glasses which are relatively easy to densify, display large pressure-induced changes in the chemical environment of the network-forming constituents, e.g., $\mathrm{B}^{\mathrm{III}}$ to $\mathrm{B}^{\mathrm{IV}}$ conversion. Since such structural rearrangement requires some energy, there is less residual energy supplied during indentation in highly compressible glasses, leading to less residual stress driving indentation cracking during unloading. Hence, we suggest that the origin of high $C R$ for the sodium aluminoborate glasses lies in their relative ease of undergoing pressure/load-driven structural rearrangements, which accompanies the large extent of volume change.

On the other hand, we acknowledge the importance of the relative contributions of densification and shear-flow to the indent volume, which has already been established in literature [15-18]. The isochoric shear-flow is theorized to cause residual stress, which drives indentation cracking. Unfortunately, the amount 
of available data focusing on both $C R, \beta$, and $V_{R}$ is currently too limited to discuss how these properties are related to the each other, and which densification parameter $\left(\beta\right.$ or $\left.V_{R}\right)$ is dominant across different glass families. Further studies are therefore required to shed light on both structural and property changes induced by sharp contact loading and isostatic compression.

\section{Conclusions}

We have examined the structure and mechanical properties of a series of sodium aluminoborate glasses with varying $\mathrm{Al} / \mathrm{B}$ ratio and tuned pressure history. Upon substitution of $\mathrm{Al}_{2} \mathrm{O}_{3}$ for $\mathrm{B}_{2} \mathrm{O}_{3}$, the charge-balancing Nacations become associated with aluminum tetrahedra at the expense of boron tetrahedra, which is in agreement with previous observations for this system. This compositional evolution leads to a decrease in density $(\rho)$, glass transition temperature $\left(T_{g}\right)$, hardness $(H)$, brittleness index $(c / a)$, and reduced modulus $\left(E_{r}\right)$, and an increase in crack resistance $(C R)$ and volume recovery ratio $\left(V_{R}\right)$ in the peralkaline region. As the $\mathrm{Al}_{2} \mathrm{O}_{3}$ content exceeds that of $\mathrm{Na}_{2} \mathrm{O}$, five-fold coordinated aluminum species form and the network connectivity thus increases and becomes more densely packed, giving rise to an increase in $\rho, T_{g}, H$, and $E$. The compositional scaling of $c / a$ and $C R$ does not exhibit any abrupt change upon crossing the peralkaline/peraluminous border.

The alumina-rich glasses have the lowest resistance to densification at elevated pressure/temperature, which manifests itself in the largest increase in the average coordination number of the Al and B networkforming species. The extent of the pressure-induced changes in short-range order of the glassy network appears to dictate the accompanying changes in density, hardness, and crack resistance. The cracking-related properties display better coherence with the ease of network compaction achieved at elevated temperature than with the ease of indentation-induced local densification of matter. We suggest that the high $C R$ for the studied series of glasses is originating from the significant changes in chemical environment achieved though large extent of network compaction. This result may be used for the design of more damage-resilient oxide glasses by designing the chemical composition. We also show that the knowledge of $V_{R}$ alone is a poor indication of the damage resilience in oxide glasses, which underlines the importance of investigation of the pressure history dependence of mechanical properties of these materials. 


\section{Acknowledgements}

The authors thank Yuanwei Chang (UCLA) for technical assistance with nanoindentation measurements and Vladimir Popok (AAU) for access to the atomic force microscope. M.M.S. acknowledges financial support from the Danish Council for Independent Research under Sapere Aude: DFF-Starting Grant (1335-00051A). A.G. acknowledges financial support from U.S. Army Research Laboratory (ARL) under the direction of Dr. Parimal Patel. M.Bauchy acknowledges financial support from the National Science Foundation under Grant No. 1562066. S.J.R. acknowledges financial support from the National Science Center of Poland under Grant No. UMO-2011/03/B/ST3/02352.

\section{References}

[1] L. Wondraczek, J.C. Mauro, J. Eckert, U. Kühn, J. Horbach, J. Deubener, T. Rouxel, Towards Ultrastrong Glasses, Adv. Mater. 23 (2011) 4578-4586. doi:10.1002/adma.201102795.

[2] G.E. Stong, The Modulus of Elasticity of Glass: I Preliminary Studies: (a) Effect of Thermal History; (b) Effect of Temperature Change, J. Am. Ceram. Soc. 20 (1937) 16-22. doi:10.1111/j.11512916.1937.tb19852.x.

[3] S.S. Kistler, Stresses in Glass Produced by Nonuniform Exchange of Monovalent Ions, J. Am. Ceram. Soc. 45 (1961) 59-68.

[4] J. Seghal, S. Ito, A New Low-Brittleness Glass in the Soda-Lime-Silica Glass Family, J. Am. Ceram. Soc. 81 (1998) 2485-2488. doi:10.1111/j.1151-2916.1998.tb02649.x.

[5] T.M. Gross, M. Tomozawa, A. Koike, A Glass with High Crack Initiation Load: Role of Fictive Temperature-Independent Mechanical Properties, Jounal of Non-Crystalline Solids. 355 (2009) $563-$ 568. doi:10.1016/j.jnoncrysol.2009.01.022.

[6] H. Morozumi, H. Nakano, S. Yoshida, J. Matsuoka, Crack Initiation Tendency of Chemically Strenghtened Glasses, Int. J. Appl. Glas. Sci. 6 (2015) 64-71. doi:10.1111/ijag.12089.

[7] G.A. Rosales-Sosa, A. Masuno, Y. Higo, H. Inoue, Crack-Resistant Al2O3-SiO2 Glasses, Sci. Rep. 6 (2016) 23620. doi:10.1038/srep23620. 
[8] A.A. Griffith, The Phenomena of Rupture and Flow in Solids, Philos. Trans. R. Soc. London. Ser. A, Contain. Pap. a Math. or Phys. Character. 221 (1921) 163-198. http://www.jstor.org/stable/91192.

[9] J.E. Neely, J.D. MacKenzie, Hardness and Low-Temperature Deformation of Silica Glass, J. Mater. Sci. 3 (1968) 603-609.

[10] K.W. Peter, Densification and Flow Phenomena of Glass in Indenation Experiments, J. Non. Cryst. Solids. 5 (1970) 103-115. doi:doi:10.1016/0022-3093(70)90188-2.

[11] B.R. Lawn, A.G. Evans, A Model for Crack Initiation in Elastic/Plastic Indentation Fields, J. Mater. Sci. 12 (1977) 2195-2199. doi:10.1007/BF00552240.

[12] A. Arora, D.B. Marshall, B.R. Lawn, Indentation Deformation/Fracture of Normal and Anomalous Glasses, J. Non. Cryst. Solids. 31 (1979) 415-428. doi:doi:10.1016/0022-3093(79)90154-6.

[13] B.R. Lawn, D.B. Marshall, Hardness, Toughness and Brittleness: An Indentation Analysis, J. Am. Ceram. Soc. 62 (1979) 347-350. doi:10.1111/j.1151-2916.1979.tb19075.x.

[14] J. Seghal, S. Ito, Brittleness of Glass, Jounal of Non-Crystalline Solids. 253 (1999) 126-132. doi:10.1016/S0022-3093(99)00348-8.

[15] S. Yoshida, J.C. Sanglebæuf, T. Rouxel, Quantitative Evaluation of Indentation-Induced Densification in Glass, J. Mater. Res. 20 (2005) 3404-3412. doi:dx.doi.org/10.1557/jmr.2005.0418.

[16] Y. Kato, H. Yamazaki, S. Yoshida, J. Matsuoka, Effect of Densification on Crack Initiation under Vickers Indentation Test, J. Non. Cryst. Solids. 356 (2010) 1768-1773. doi:10.1016/j.jnoncrysol.2010.07.015.

[17] P. Sellapan, T. Rouxel, F. Celarie, E. Becker, P. Houizot, R. Conradt, Composition Dependence of Indentation Deformation and Indentation Cracking in Glass, Acta Mater. 61 (2013) 5949-5965. doi:doi:10.1016/j.actamat.2013.06.034.

[18] T. Rouxel, Driving Force for Indentation Cracking in Glass: Composition, Pressure and Temperature Dependence, Philos. Trans. R. Soc. London A Math. Phys. Eng. Sci. 373 (2015). doi:10.1098/rsta.2014.0140.

[19] W.H. Zachariasen, The Atomic Arrangement in Glass, J. Am. Chem. Soc. 54 (1932) 3841-3851. doi:10.1021/ja01349a006. 
[20] P.Y. Huang, S. Kurasch, A. Srivastava, V. Skakalova, J. Kotakoski, A. V. Krasheninnikov, R. Hovden, Q. Mao, J.C. Meyer, J. Smet, D.A. Muller, U. Kaiser, Direct Imaging of a Two-Dimensional Silica Glass on Graphene, Nano Lett. 12 (2012) 1081-1086. doi:10.1021/nl204423x.

[21] T. Rouxel, H. Ji, T. Hammouda, A. Moréac, Poisson's Ratio and the Densification of Glass under High Pressure, Phys. Rev. Lett. 100 (2008) 225501. doi:http://dx.doi.org/10.1103/PhysRevLett.100.225501.

[22] J.S. Jen, M.R. Kalinowski, An ESCA Study of Briding to Non-Bridging Oxygen Ratio in Sodium Silicate Glass and the Correlations to Glass Density and Refractive Index, Jounal of Non-Crystalline Solids. 38-39 (1980) 21-26. doi:10.1016/0022-3093(80)90388-9.

[23] S. Yoshida, Y. Hayashi, A. Konno, T. Sugawara, Y. Miura, J. Matsuoka, Indentation Induced Densification of Sodium Borate Glasses, Phys. Chem. Glas. Eur. J. Glas. Sci. Technol. B. 50 (2009) 63-70.

[24] R. Gresch, W. Müller-Warmuth, H. Dutz, 11B and 27Al NMR Studies of Glasses in the System Na2O-B2O3-A12O3 (“NABAL”), J. Non. Cryst. Solids. 21 (1976) 31-40. doi:doi:10.1016/00223093(76)90088-0.

[25] L. Züchner, J.C.C. Chan, W. Müller-Warmuth, H. Eckert, Short-Range Order and Site Connectivities in Sodium Aluminoborate Glasses: I. Quantification of Local Environments by High-Resolution 11B, 23Na, and 27Al Solid-State NMR, J. Phys. Chem. B. 102 (1998) 4495-4506. doi:10.1021/jp980587s.

[26] J.C.C. Chan, M. Bertmer, H. Eckert, Site Connectivities in Amorphous Materials Studied by DoubleResonance NMR of Quadrupolar Nuclei: High Resolution 11B $\leftrightarrow 27 \mathrm{Al}$ Spectroscopy of Aluminoborate Glasses, J. Am. Chem. Soc. 121 (1999) 5238-5248. doi:10.1021/ja983385i.

[27] M. Bertmer, L. Züchner, J.C.C. Chan, H. Eckert, Short and Medium Range Order in Sodium Aluminoborate Glasses. 2. Site Connectivities and Cation Distributions Studied by Rotational Echo Double Resonance NMR Spectroscopy, J. Phys. Chem. B. 104 (2000) 6541-6553. doi:10.1021/jp9941918.

[28] H. Doweidar, Y.M. Moustafa, S. Abd El-Maksoud, H. Silim, Properties of Na2O-Al2O3-B2O3 Glasses, Mater. Sci. Eng. A. 301 (2001) 207-212. doi:doi:10.1016/S0921-5093(00)01786-X. 
[29] L.-S. Du, J.F. Stebbins, Site Connectivities in Sodium Aluminoborate Glasses: Multinuclear and Multiple Quantum NMR Results, Solid State Nucl. Magn. Reson. 27 (2005) 37-49.

doi:doi:10.1016/j.ssnmr.2004.08.003.

[30] SciGlass Web, (n.d.). http://www.sciglassweb.com/default.jsp (accessed January 2, 2017).

[31] M.M. Smedskjaer, S.J. Rzoska, M. Bockowski, J.C. Mauro, Mixed Alkaline Earth Effect in the Compressibility of Aluminosilicate Glasses, J. Chem. Phys. 140 (2014) 54511. doi:dx.doi.org/10.1063/1.4863998.

[32] D. Massiot, F. Fayon, M. Capron, I. King, S. Le Calvé, B. Alonso, J.-O. Duran, B. Bujoli, Z. Gan, G. Hoatson, Modelling One- and Two-Dimensional Solid-State NMR Spectra, Magn. Reson. Chem. 40 (2002) 70-76. doi:10.1002/mrc.984.

[33] D. Massiot, C. Bessada, J.P. Coutures, F. Taulelle, A Quantitative Study of 27Al MAS NMR in Crystalline YAG, J. Magn. Reson. 90 (1990) 231-242. doi:10.1016/0022-2364(90)90130-2.

[34] W.C. Oliver, G.M. Pharr, An Improved Technique for Determining Hardness and Elastic Modulus Using Load and Displacement Sensing Indentation Experiments, J. Mater. Res. 7 (1992) 1564-1583. doi:dx.doi.org/10.1557/JMR.1992.1564.

[35] J. Allwardt, J. Stebbins, B. Schmidt, D. Frost, A. Withers, M. Hirschmann, Aluminum Coordination and the Densification of High-Pressure Aluminosilicate Glasses, Am. Mineral. 90 (2005) 1218-1222. doi:dx.doi.org/10.2138/am.2005.1836.

[36] M. Grimsditch, A. Polian, A.C. Wright, Irreversible Structural Changes in Vitreous B2O3 Under Pressure, Phys. Rev. B. 54 (1996) 152-155. doi:dx.doi.org/10.1103/ PhysRevB.54.152.

[37] J. Wu, J. Deubener, J.F. Stebbins, L. Grygarova, H. Behrens, L. Wondraczek, Y. Yue, Structural response of a highly viscous aluminoborosilicate melt to isotropic and anisotropic compressions, J. Chem. Phys. 131 (2009) 104504. doi:10.1063/1.3223282.

[38] M.N. Svenson, T.K. Bechgaard, S.D. Fuglsang, R.H. Pedersen, A.Ø. Tjell, M.B. Østergaard, R.E. Youngman, J.C. Mauro, S.J. Rzoska, M. Bockowski, M.M. Smedskjaer, Composition-StructureProperty Relations of Compressed Borosilicate Glasses, Phys. Rev. Appl. 2 (2014) 24006. doi:10.1103/PhysRevApplied.2.024006. 
[39] M.B. Østergaard, R.E. Youngman, M.N. Svenson, S.J. Rzoska, M. Bockowski, L.R. Jensen, M.M. Smedskjaer, Temperature-Dependent Densification of Sodium Borosilicate Glass, RSC Adv. 5 (2015) 78845-78851. doi:10.1039/C5RA16219J.

[40] T.K. Bechgaard, A. Goel, R.E. Youngman, J.C. Mauro, S.J. Rzoska, M. Bockowski, L.R. Jensen, M.M. Smedskjaer, Structure and Mechanical Properties of Compressed Aluminosilicate Glasses: Role of Non-Bridging Oxygens, Jounal of Non-Crystalline Solids. 441 (2016) 49-57. doi:10.1016/j.jnoncrysol.2016.03.011.

[41] X. Xue, J.F. Stebbins, 23 Na NMR Chemical Shifts and Local Na Coordination Environments in Silicate Crystals, Melts and Glasses, Phys. Chem. Miner. 20 (1993) 297-307. doi:10.1007/BF00215100.

[42] A.M. George, S. Sen, J.F. Stebbins, 23Na Chemical Shifts and Local Structure in Crystalline, Glassy and Molten Sodium Borates and Germanates, Solid State Nucl. Magn. Reson. 10 (1997) 9-17. doi:10.1016/S0926-2040(97)00072-6.

[43] M.N. Svenson, L.M. Thirion, R.E. Youngman, J.C. Mauro, S.J. Rzoska, M. Bockowski, M.M. Smedskjaer, Pressure-Induced Changes in Interdiffusivity and Compressive Stress in Chemically Strenghtened Glass, ACS Appl. Mater. Interfaces. 6 (2014) 10436-10444. doi:10.1021/am5019868.

[44] A.H. Silver, P.J. Bray, Nuclear Magnetic Resonance Absorption in Glass. I. Nuclear Quadrupole Effects in Boron Oxide, Soda-Boric Oxide, and Borosilicate Glasses, J. Chem. Phys. 29 (1958) 984. doi:dx.doi.org/10.1063/1.1744697.

[45] M.M. Smedskjaer, J.C. Mauro, Y. Yue, Prediction of Glass Hardness Using Temperature-Dependent Constraint Theory, Phys. Rev. Lett. 105 (2010) 115503. doi:dx.doi.org/10.1103/PhysRevLett.105.115503.

[46] J.E. Shelby, Viscosity and Thermal Expansion of Lithium Aluminosilicate Glasses, J. Appl. Phys. 49 (1978) 5885. doi:10.1063/1.324553.

[47] A. Makishima, J.D. Mackenzie, Direct Calculation of Young's Modulus of Glass, J. Non. Cryst. Solids. 12 (1973) 35-45. doi:10.1016/0022-3093(73)90053-7.

[48] R.D. Shannon, Revised effective ionic radii and systematic studies of interatomic distances in halides 
and chalcogenides, Acta Crystallogr. Sect. A. 32 (1976) 751-767. doi:10.1107/S0567739476001551.

[49] Q. Zhao, M. Guerette, L. Huang, Nanoindentation and Brillouin Light Scattering Studies of Elastic Moduli of Sodium Silicate Glasses, J. Non. Cryst. Solids. 358 (2012) 652-657. doi:10.1016/j.jnoncrysol.2011.10.034.

[50] S. Striepe, M.M. Smedskjaer, J. Deubener, U. Bauer, H. Behrens, M. Potuzak, R.E. Youngman, J.C. Mauro, Y. Yue, Elastic and Micromechanical Properties of Isostatically Compressed Soda-LimeBorate Glasses, Jounal of Non-Crystalline Solids. 364 (2013) 44-52. doi:10.1016/j.jnoncrysol.2013.01.009.

[51] K.G. Aakermann, K. Januchta, J.A.L. Pedersen, M.N. Svenson, S.J. Rzoska, M. Bockowski, J.C. Mauro, M. Guerette, L. Huang, M.M. Smedskjaer, Indentation deformation mechanism of isostatically compressed mixed alkali aluminosilicate glasses, J. Non. Cryst. Solids. 426 (2015) 175183. doi:http://dx.doi.org/10.1016/j.jnoncrysol.2015.06.028.

[52] B.R. Lawn, V.R. Howes, Elastic Recovery at Hardness Indentations, J. Mater. Sci. 16 (1981) 27452752. doi:10.1007/BF02402837.

[53] G.R. Anstis, P. Chantikul, B.R. Lawn, D.B. Marshall, A Critical Evaluation of Indentation Techniques for Measuring Fracture Toughness: I, Direct Crack Measurements, J. Am. Ceram. Soc. 64 (1981) 533-538. doi:10.1111/j.1151-2916.1981.tb10320.x.

[54] E.H. Yoffe, Elastic Stress Fields Caused by Indenting Brittle Materials, Philos. Mag. A. 46 (1982) 617-628. doi:10.1080/01418618208236917.

[55] M.N. Svenson, M. Guerette, L. Huang, N. Lönnroth, J.C. Mauro, S.J. Rzoska, M. Bockowski, M.M. Smedskjaer, Universal Behavior of Changes in Elastic Moduli of Hot Compressed Oxide Glasses, Chem. Phys. Lett. 651 (2016) 88-91. doi:10.1016/j.cplett.2016.03.025.

[56] E.O. Bernhardt, On Microhardness of Solids at the Limit of Kick's Similarity Law, Zeitschrift Für Met. 33 (1941) 135-144.

[57] N.A. Sakharova, J. V. Fernandes, J.M. Antunes, M.C. Oliveira, Comparison between Berkovich, Vickers and Conical Indentation Tests: A Three-Dimensional Numerical Simulation Study, Int. J. Solids Struct. 46 (2009) 1095-1104. doi:10.1016/j.ijsolstr.2008.10.032. 
[58] Y. Kato, H. Yamazaki, Y. Kubo, S. Yoshida, J. Matsuoka, T. Akai, Effect of B2O3 Content on Crack Inititation under Vickers Indentation Test, J. Ceram. Soc. Japan. 118 (2010) 792-798. doi:10.2109/jcersj2.118.792.

[59] R. Limbach, A. Winterstein-Beckmann, J. Dellith, D. Möncke, L. Wondraczek, Plasticity, Crack Initiation and Defect Resistance in Alkali-Borosilicate Glasses: From Normal to Anomalous Behavior, J. Non. Cryst. Solids. 417 (2015) 15-27. doi:doi:10.1016/j.jnoncrysol.2015.02.019.

[60] S. Yoshida, Y. Nishikubo, A. Konno, T. Sugwawa, Y. Miura, J. Matsuoka, Fracture- and IndentationInduced Structural Changes of Sodium Borosilicate Glasses, Int. J. Appl. Glas. Sci. 3 (2012) 3-13. doi:10.1111/j.2041-1294.2011.00077.x.

[61] C. Hermansen, J. Matsuoka, S. Yoshida, H. Yamazaki, Y. Kato, Y.Z. Yue, Densification and Plastic Deformation under Microindentation in Silicate Glasses and the Relation to Hardness and Crack Resistance, Jounal of Non-Crystalline Solids. 364 (2013) 40-43. doi:10.1016/j.jnoncrysol.2012.12.047.

[62] J. Kjeldsen, M.M. Smedskjaer, J.C. Mauro, Y. Yue, Hardness and Incipient Plasticity in Silicate Glasses: Origin of the Mixed Modifier Effect, Appl. Phys. Lett. 104 (2014) 51913. doi:dx.doi.org/10.1063/1.4864400.

[63] M. Barlet, J.-M. Delaye, T. Charpentier, M. Gennison, D. Bonamy, T. Rouxel, C.L. Rountree, Hardness and Toughness of Sodium Borosilicate Glasses via Vicker's Indentations, Jounal of NonCrystalline Solids. 417 (2015) 66-79. doi:10.1016/j.jnoncrysol.2015.02.005. 
Table 1. Analyzed chemical compositions, glass transition temperature $\left(T_{\mathrm{g}}\right)$, density $(\rho)$, atomic packing fraction $\left(C_{\mathrm{g}}\right)$, and plastic compressibility $(\beta)$ of the as-prepared sodium aluminoborate glasses. The errors in $T_{\mathrm{g}}, \rho, C_{\mathrm{g}}$, and $\beta$ do not exceed $\pm 2{ }^{\circ} \mathrm{C}, \pm 0.001 \mathrm{~g} / \mathrm{cm}^{3}, \pm 0.001$, and $\pm 0.002 \mathrm{GPa}^{-1}$, respectively.

\begin{tabular}{lccccccc}
\hline Glass-ID & $\begin{array}{c}{\left[\mathrm{Na}_{2} \mathrm{O}\right]} \\
(\mathrm{mol} \%)\end{array}$ & $\begin{array}{c}{\left[\mathrm{Al}_{2} \mathrm{O}_{3}\right]} \\
(\mathrm{mol} \%)\end{array}$ & $\begin{array}{c}{\left[\mathrm{B}_{2} \mathrm{O}_{3}\right]} \\
(\mathrm{mol} \%)\end{array}$ & $\begin{array}{c}T_{g} \\
\left({ }^{\circ} \mathrm{C}\right)\end{array}$ & $\begin{array}{c}\rho \\
\left(\mathrm{g} / \mathrm{cm}^{3}\right)\end{array}$ & $\begin{array}{c}C_{\mathrm{g}} \\
(-)\end{array}$ & $\begin{array}{c}\beta \\
\left(\mathrm{GPa}^{-1}\right)\end{array}$ \\
\hline NAB-5 & 25.7 & 5.0 & 69.3 & 474 & 2.257 & 0.548 & 0.044 \\
NAB-10 & 25.2 & 10.3 & 64.5 & 468 & 2.244 & 0.534 & 0.049 \\
NAB-15 & 25.2 & 15.3 & 59.5 & 455 & 2.242 & 0.522 & 0.051 \\
NAB-20 & 25.5 & 20.4 & 54.1 & 451 & 2.240 & 0.510 & 0.061 \\
NAB-24 & 25.5 & 24.4 & 50.1 & 446 & 2.253 & 0.502 & 0.062 \\
NAB-28 & 25.2 & 28.0 & 46.7 & 458 & 2.273 & 0.502 & 0.061 \\
NAB-30 & 25.0 & 30.2 & 44.8 & 470 & 2.290 & 0.502 & 0.062 \\
\hline
\end{tabular}

Table 2. Fraction of aluminum and boron species in sodium aluminoborate glasses as determined from the

${ }^{11} \mathrm{~B}$ and ${ }^{27} \mathrm{Al}$ MAS NMR spectroscopy analyses. The errors in the fractions of boron and aluminium do not exceed \pm 0.01 and \pm 0.02 , respectively.

\begin{tabular}{lccccc}
\hline Glass-ID & $\mathrm{B}^{\mathrm{III}}$ & $\mathrm{B}^{\mathrm{IV}}$ & $\mathrm{Al}^{\mathrm{IV}}$ & $\mathrm{Al}^{\mathrm{V}}$ & $\mathrm{Al}^{\mathrm{VI}}$ \\
\hline NAB-5 (as-prepared) & 0.67 & 0.33 & 0.97 & 0.03 & - \\
NAB-15 (as-prepared) & 0.80 & 0.20 & 0.97 & 0.03 & - \\
NAB-24 (as-prepared) & 0.92 & 0.08 & 0.96 & 0.04 & - \\
NAB-30 (as-prepared) & 0.97 & 0.03 & 0.91 & 0.07 & 0.01 \\
NAB-5 (compressed) & 0.66 & 0.34 & 0.89 & 0.07 & 0.04 \\
NAB-15 (compressed) & 0.76 & 0.24 & 0.90 & 0.07 & 0.03 \\
NAB-24 (compressed) & 0.87 & 0.13 & 0.86 & 0.11 & 0.03 \\
NAB-30 (compressed) & 0.92 & 0.08 & 0.79 & 0.17 & 0.04 \\
\hline
\end{tabular}


Figure 1. (a) ${ }^{11} \mathrm{~B}$ MAS NMR and (b) ${ }^{27} \mathrm{Al}$ MAS NMR spectra for the as-prepared (solid lines) and compressed (dashed lines) sodium aluminoborate glasses. Resonances due to three-fold boron $\left(\mathrm{B}^{\mathrm{III}}\right)$, fourfold boron $\left(\mathrm{B}^{\mathrm{IV}}\right)$, four-fold aluminium $\left(\mathrm{Al}^{\mathrm{IV}}\right)$, five-fold aluminium $\left(\mathrm{Al}^{\mathrm{V}}\right)$, and six-fold aluminium $\left(\mathrm{Al}^{\mathrm{VI}}\right)$ are indicated.

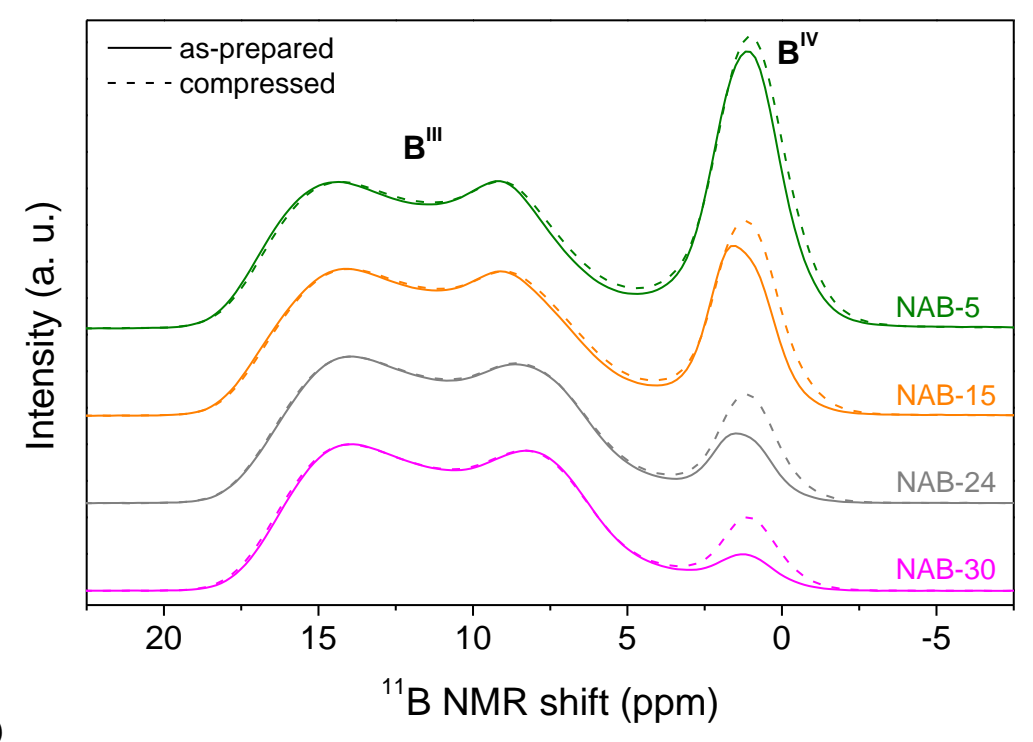

(a)

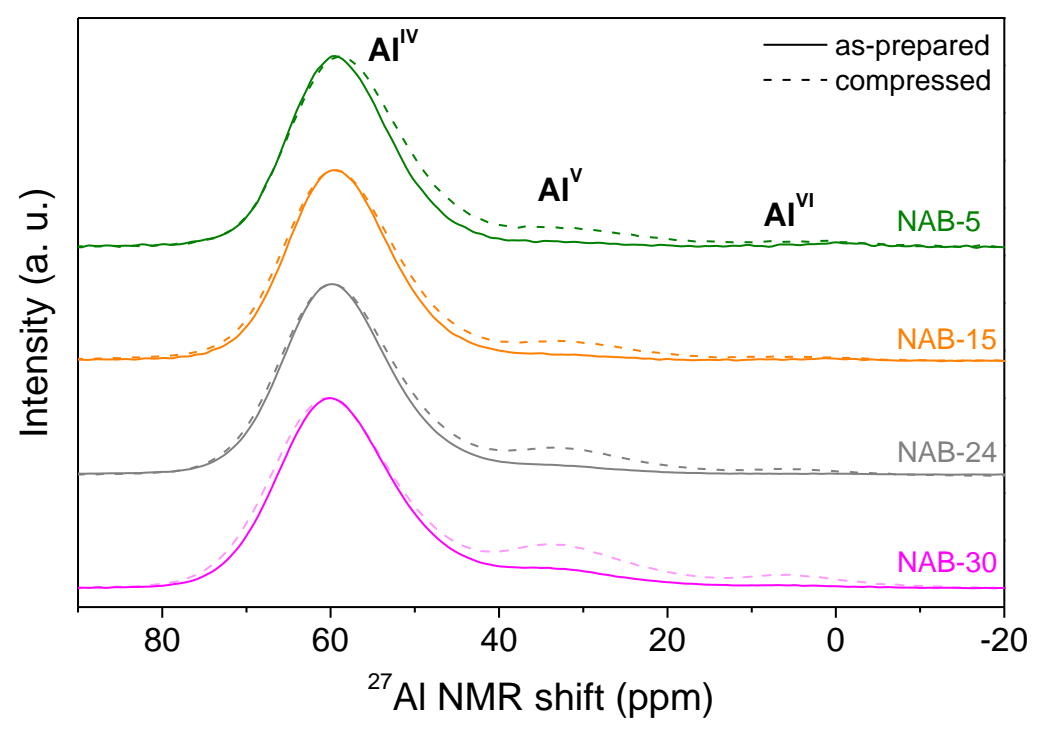

(b) 
Figure 2. Composition dependence of the fractions of aluminum and boron network-forming units in the asprepared (solid lines) and compressed (dashed lines) sodium aluminoborate glasses. The fractions are calculated based on the deconvoluted MAS NMR spectra in Figure 1 and represent the amounts of the different network-forming units relative to the combined molar contents of $\mathrm{Al}_{2} \mathrm{O}_{3}$ and $\mathrm{B}_{2} \mathrm{O}_{3}$. The errors in the fractions of boron and aluminium do not exceed \pm 0.01 and \pm 0.02 , respectively.

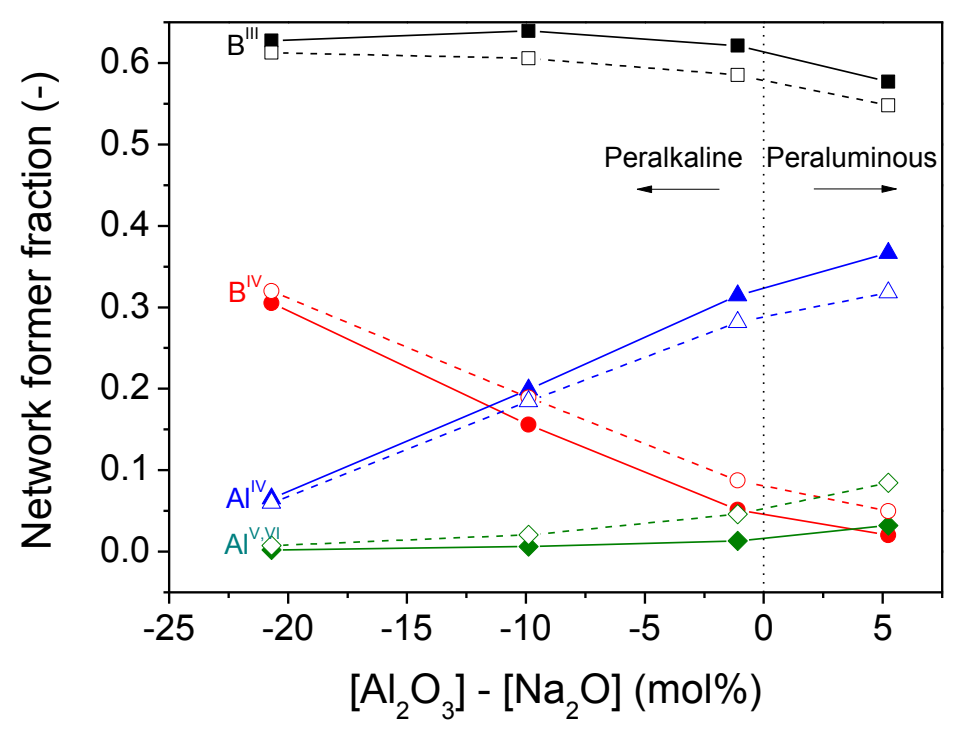


Figure 3. (a) ${ }^{23} \mathrm{Na}$ MAS NMR spectra recorded for sodium aluminoborate glasses. (b) Composition dependence of ${ }^{23} \mathrm{Na}$ isotropic chemical shift.

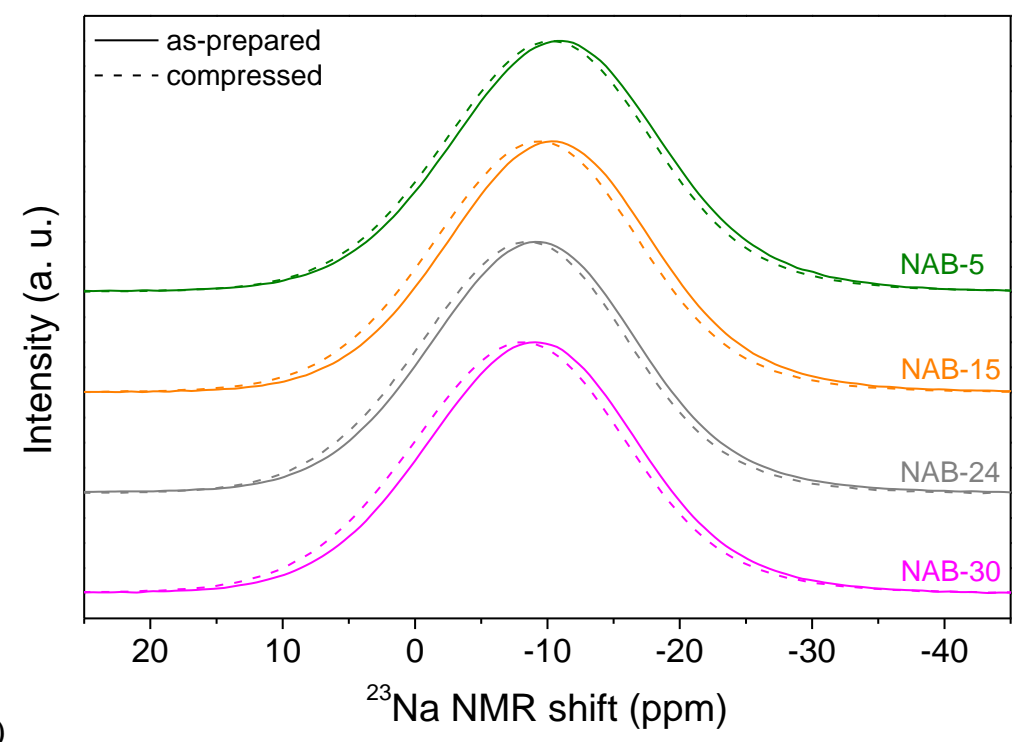

(a)

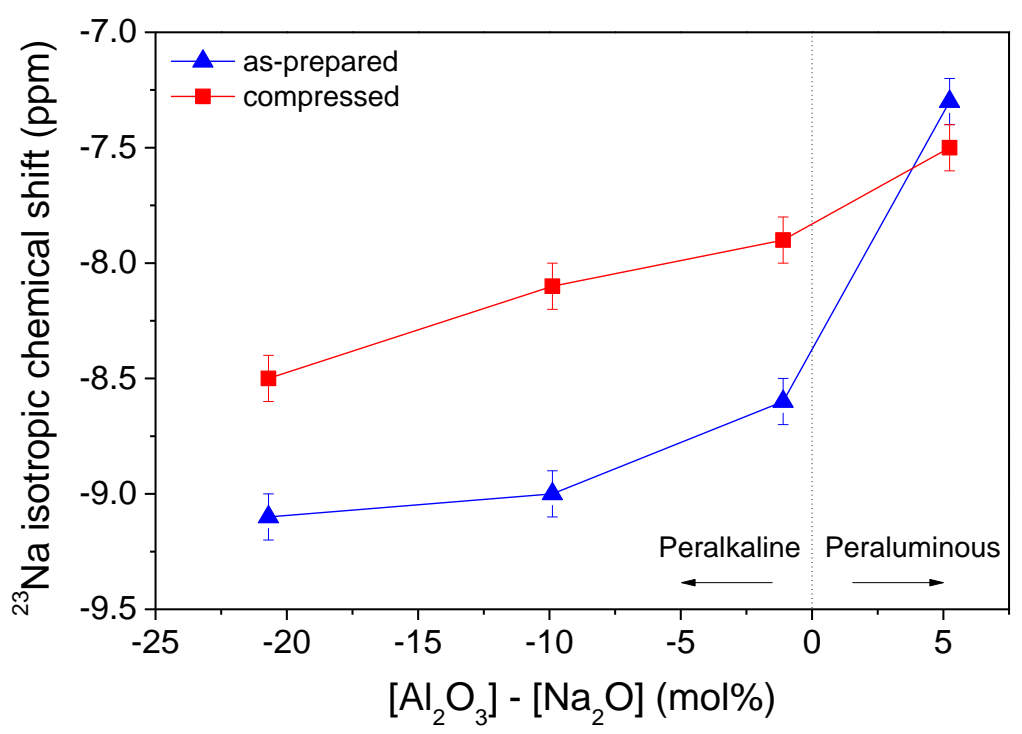


Figure 4. Composition dependence of glass transition temperature $\left(T_{\mathrm{g}}\right)$ for sodium aluminoborate glasses. The error in $T_{\mathrm{g}}$ is around $\pm 2{ }^{\circ} \mathrm{C}$. The dotted line represents the border between the peralkaline and peraluminous regions.

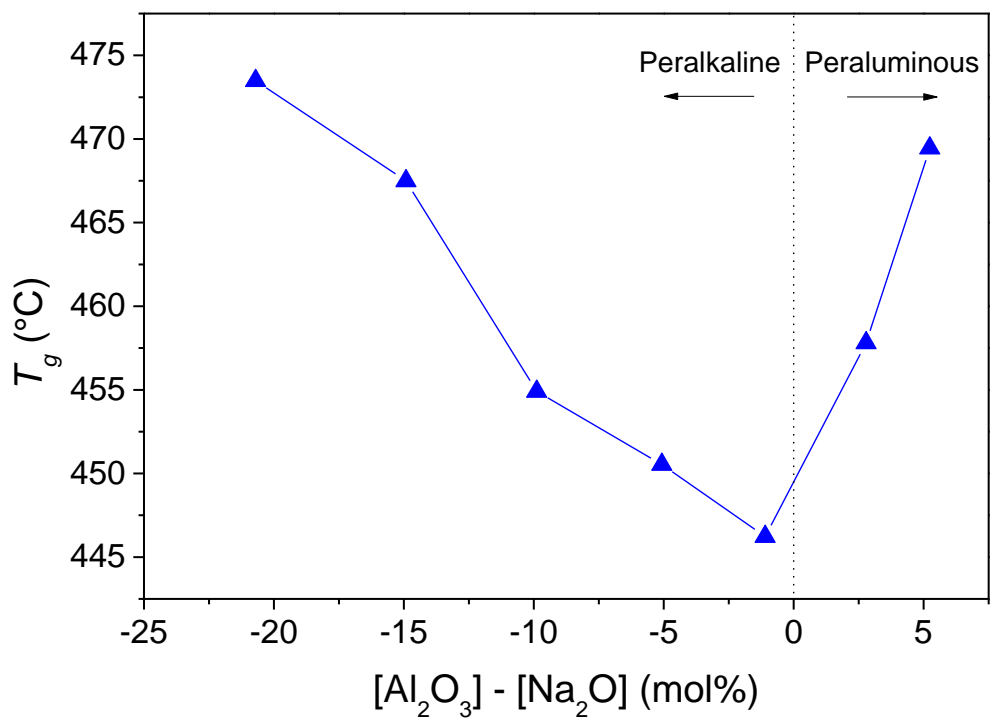


Figure 5. Composition dependence of (a) density ( $\rho$ ) and (b) plastic compressibility $(\beta)$ for sodium aluminoborate glasses. The error bars for density values are smaller than the size of the symbols, while the errors in plastic compressibility do not exceed $\pm 0.002 \mathrm{GPa}^{-1}$. The dotted line represents the border between the peralkaline and peraluminous region. Inset in (b): Correlation between $\beta$ and atomic packing density $\left(C_{g}\right)$.

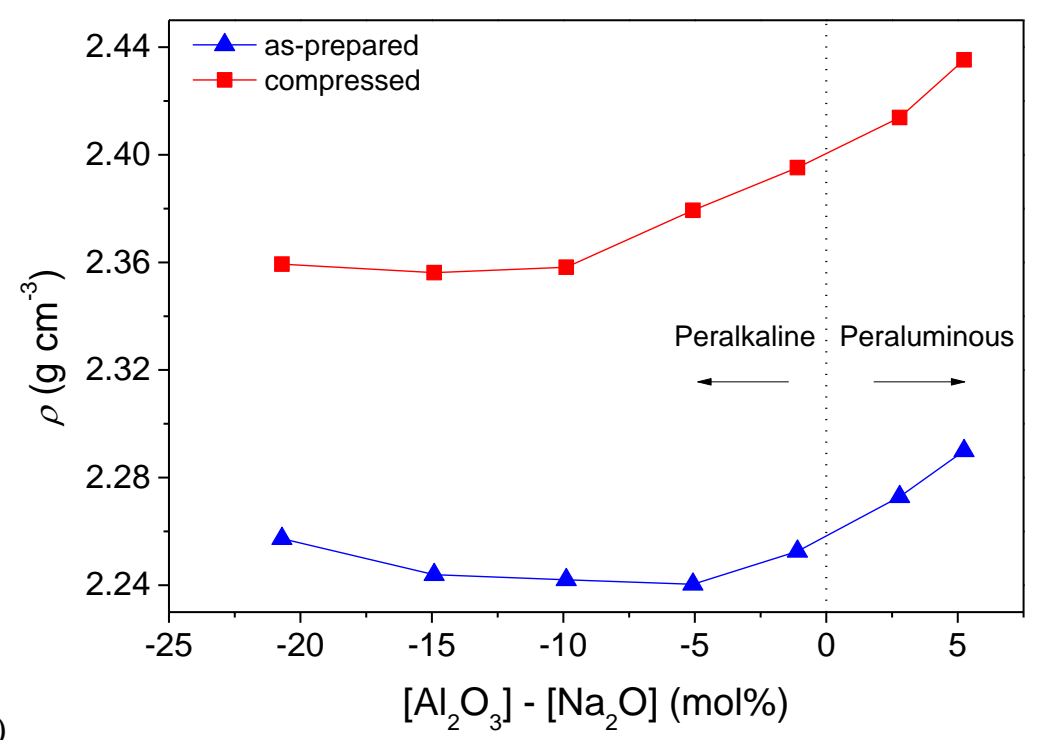

(a)

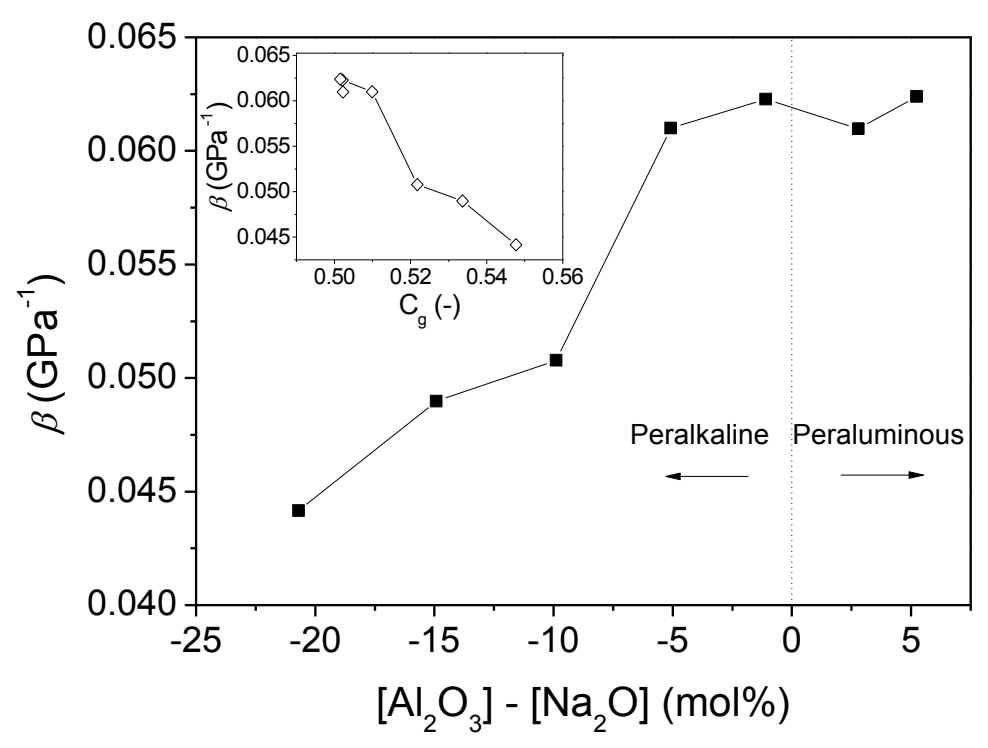

(b) 
Figure 6. Composition dependence of (a) reduced modulus $\left(E_{r}\right)$ and (b) hardness $\left(H_{\text {nano }}\right)$ measured by nanoindentation for as-prepared and compressed sodium aluminoborate glasses. The dotted line represents the border between the peralkaline and peraluminous regions. The error bars represent the standard deviation of at least ten indentation cycles.

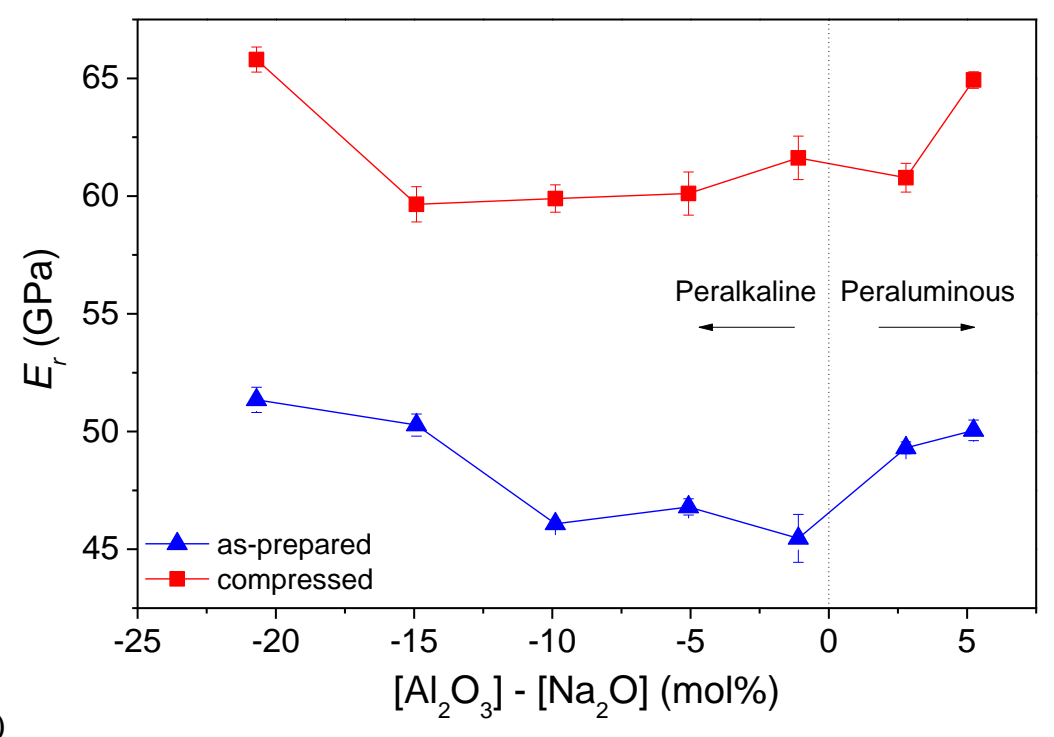

(a)

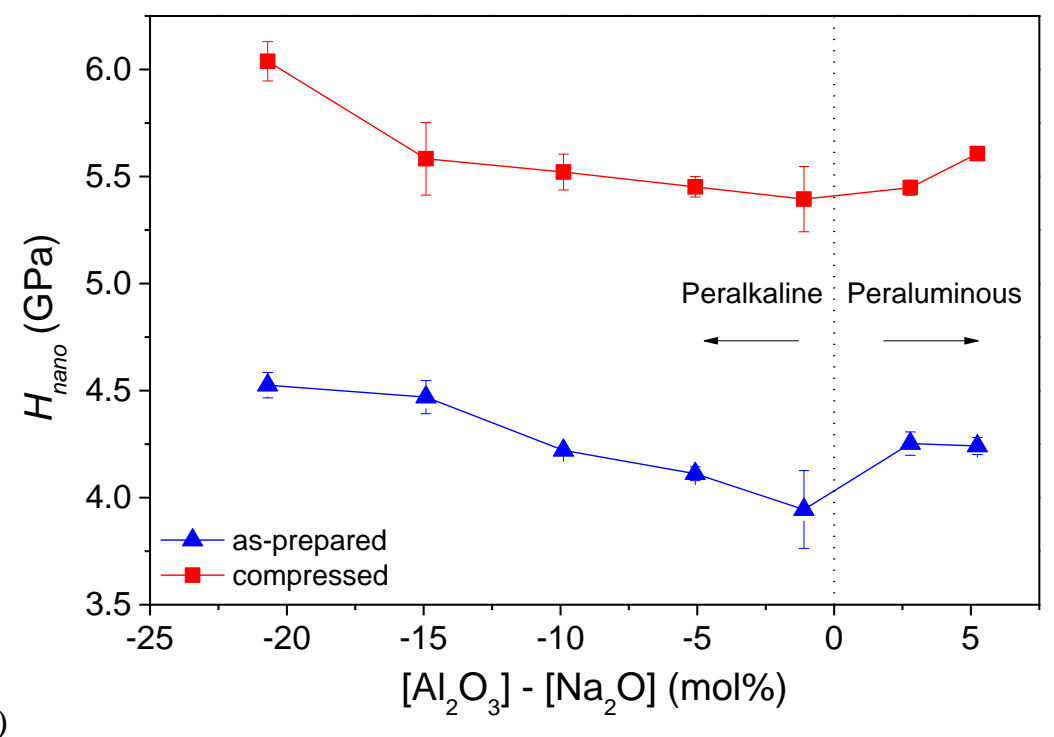


Figure 7. (a) Composition dependence of Vickers hardness $\left(H_{V}\right)$ for as-prepared and compressed sodium aluminoborate glasses. The dotted line represents the border between the peralkaline and peraluminous region. The error bars represent standard deviation of at least thirty indentations. (b) Correlation between the pressure-induced change in $H_{V}\left(\Delta H_{V} /\left(H_{V, i} P\right)\right)$ and plastic compressibility $(\beta)$.

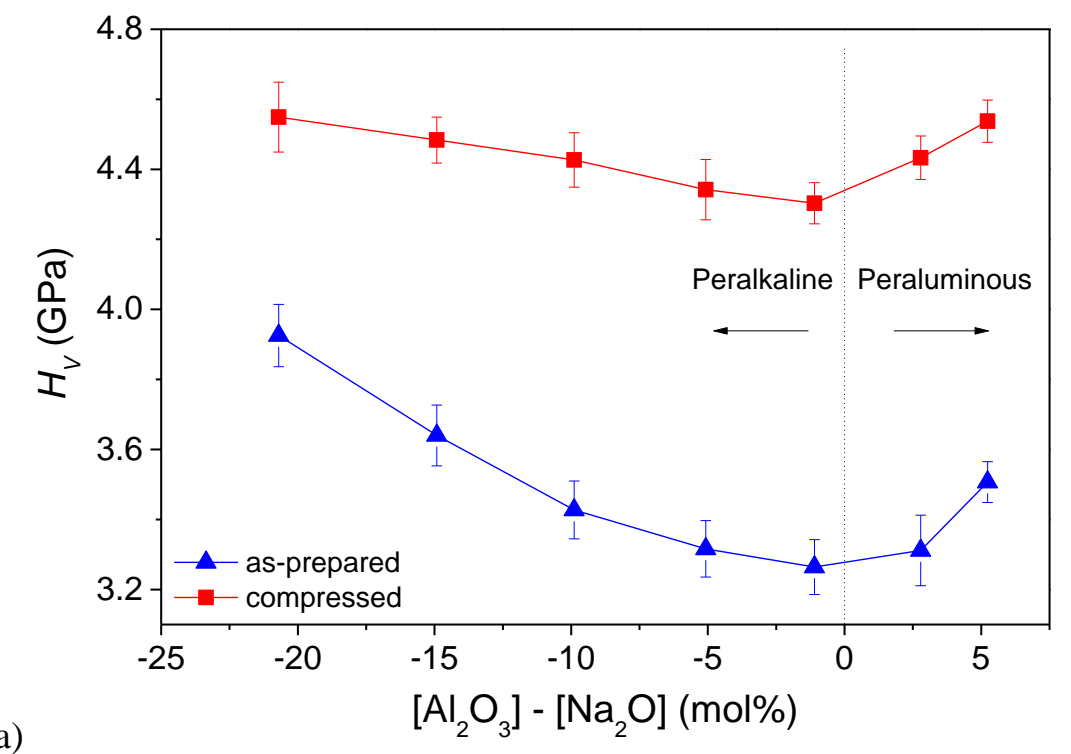

(a)

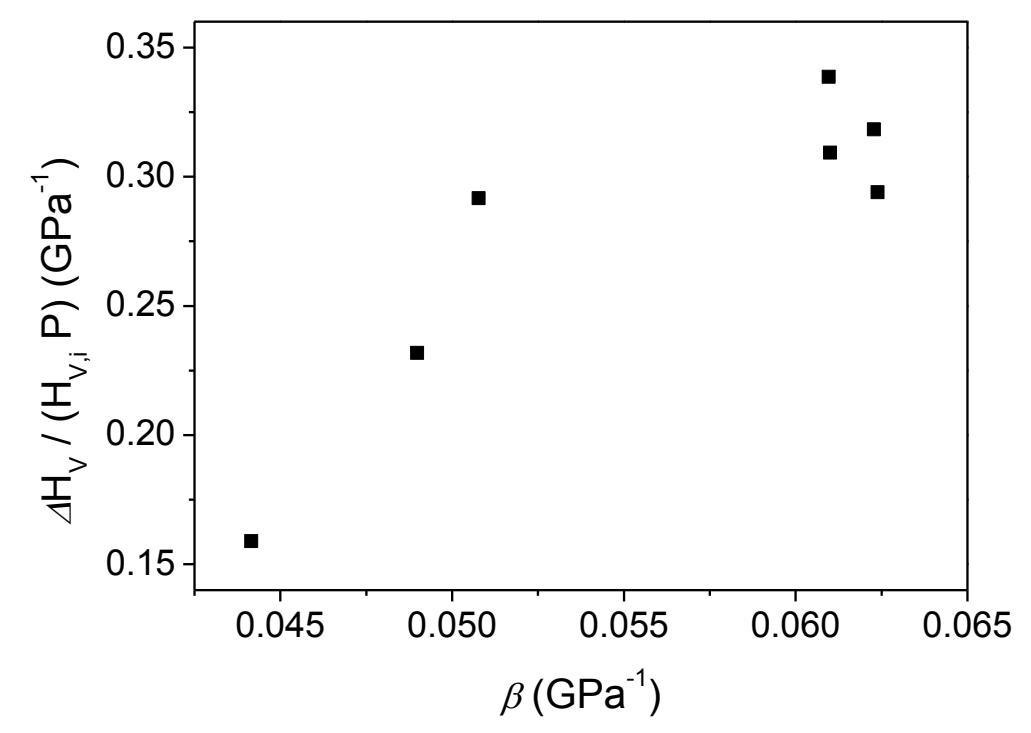


Figure 8. Indent images for representative as-prepared glass samples with varying indentation load and chemical composition.

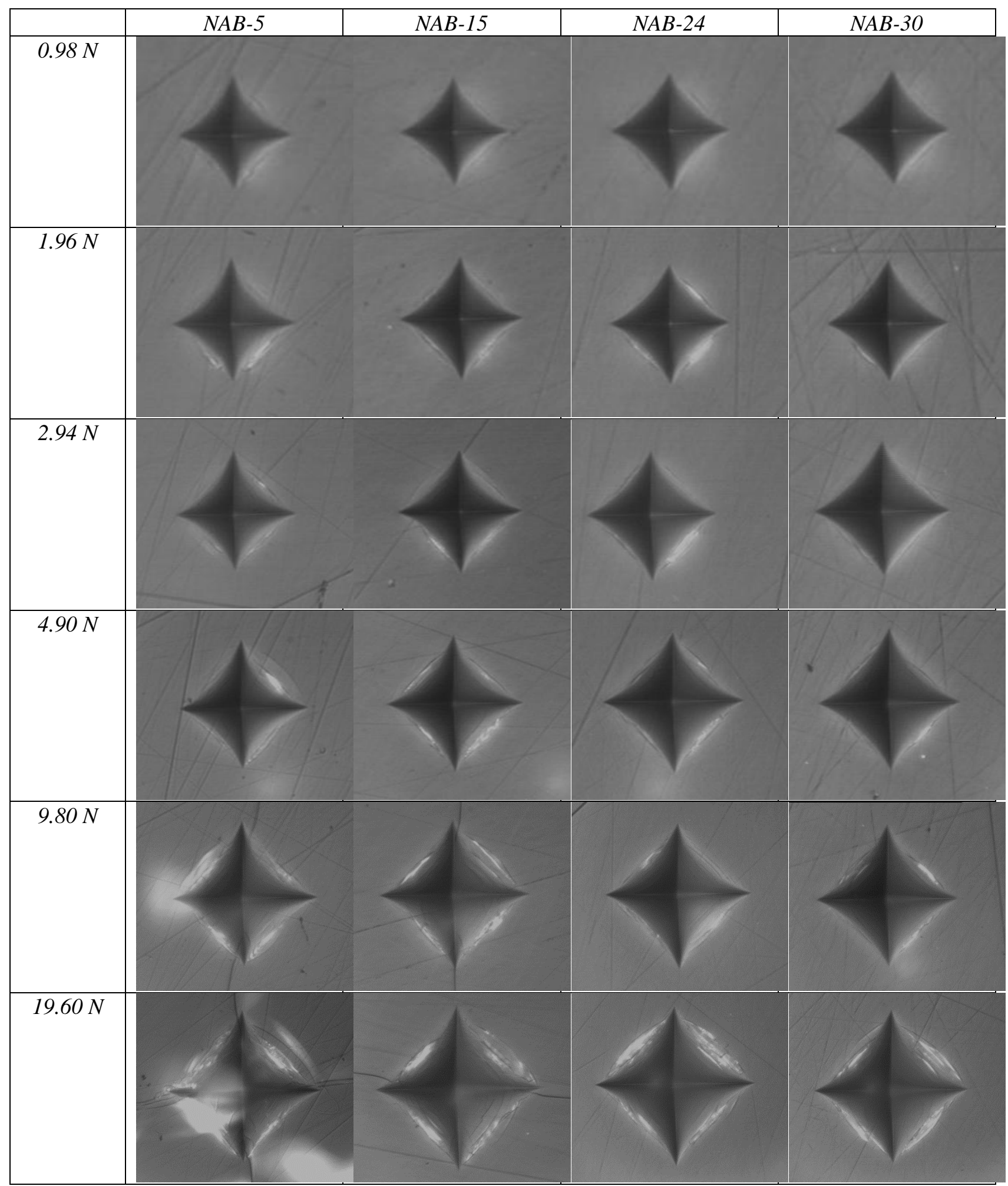


Figure 9. Indent images for representative compressed glass samples with varying indentation load and chemical composition.

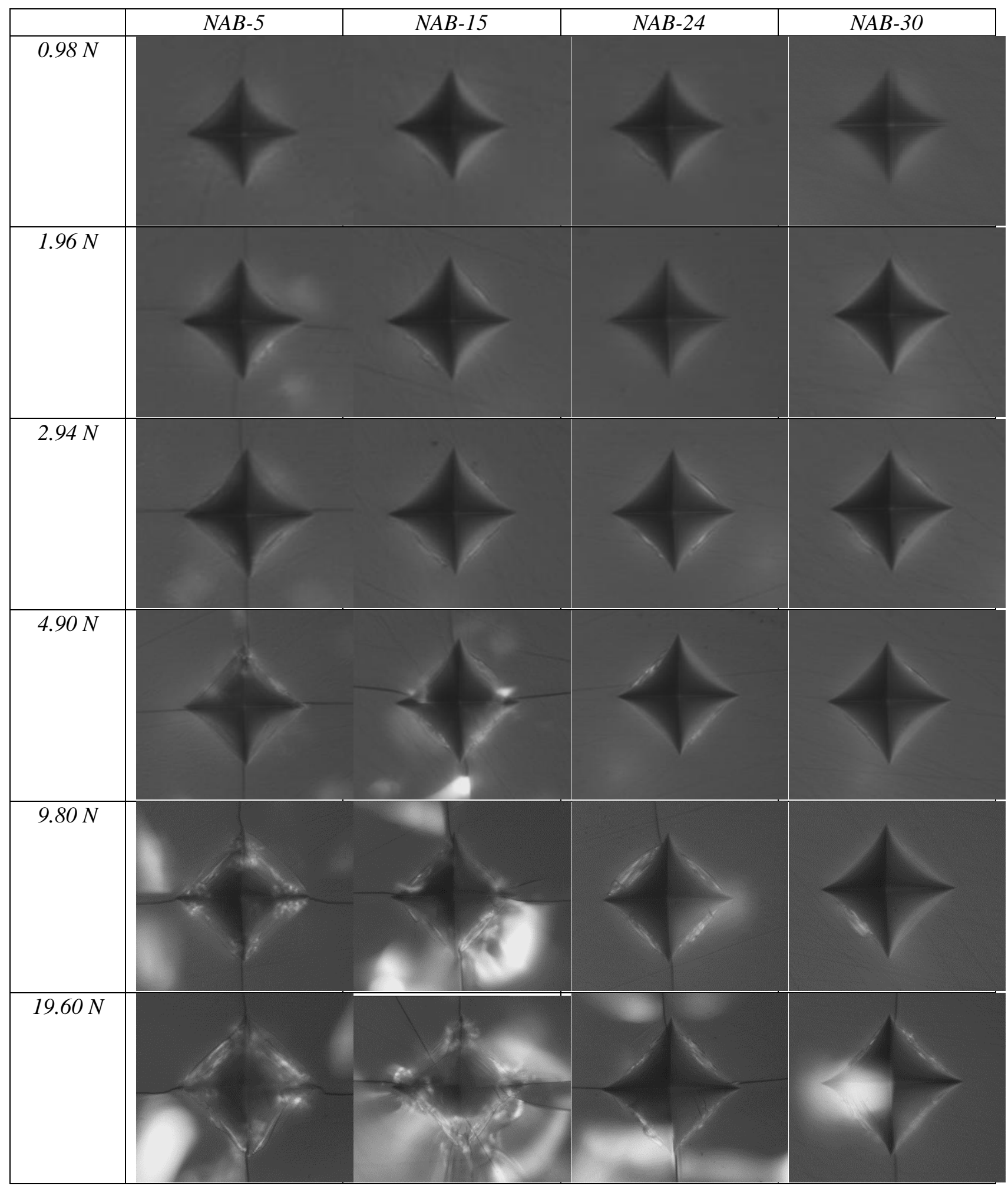


Figure 10. Crack probability as a function of applied indentation for (a) as-prepared and (b) compressed sodium aluminoborate glasses. Data points represent the experimental results and the solid lines represent sigmoidal functions fitted to the data.

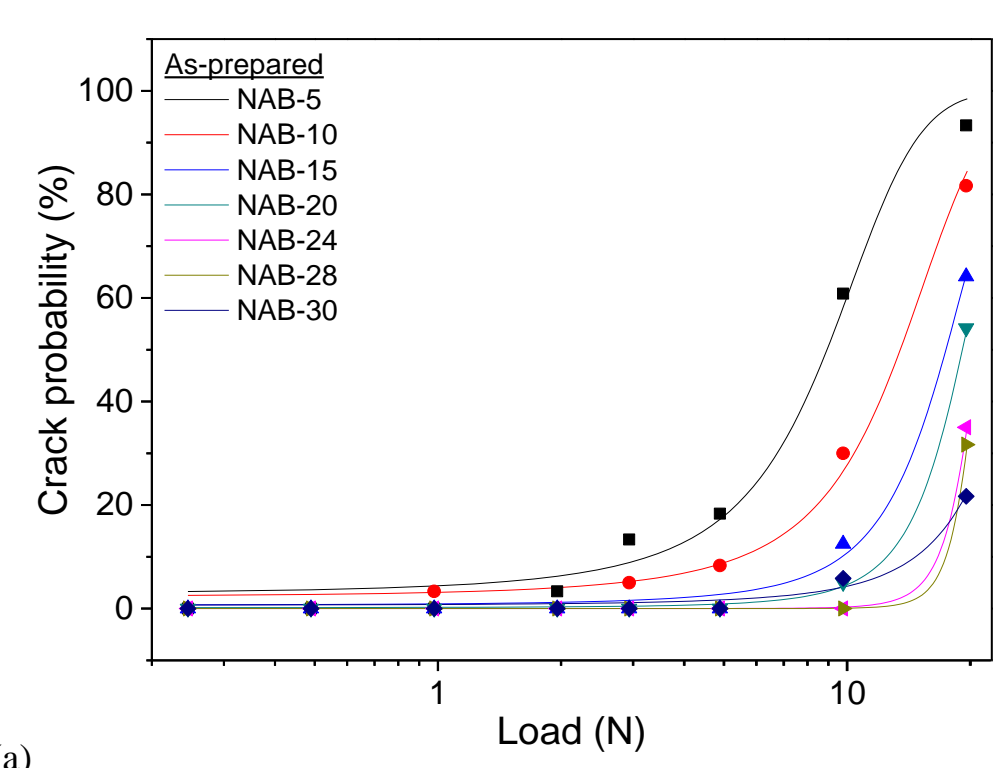

(a)

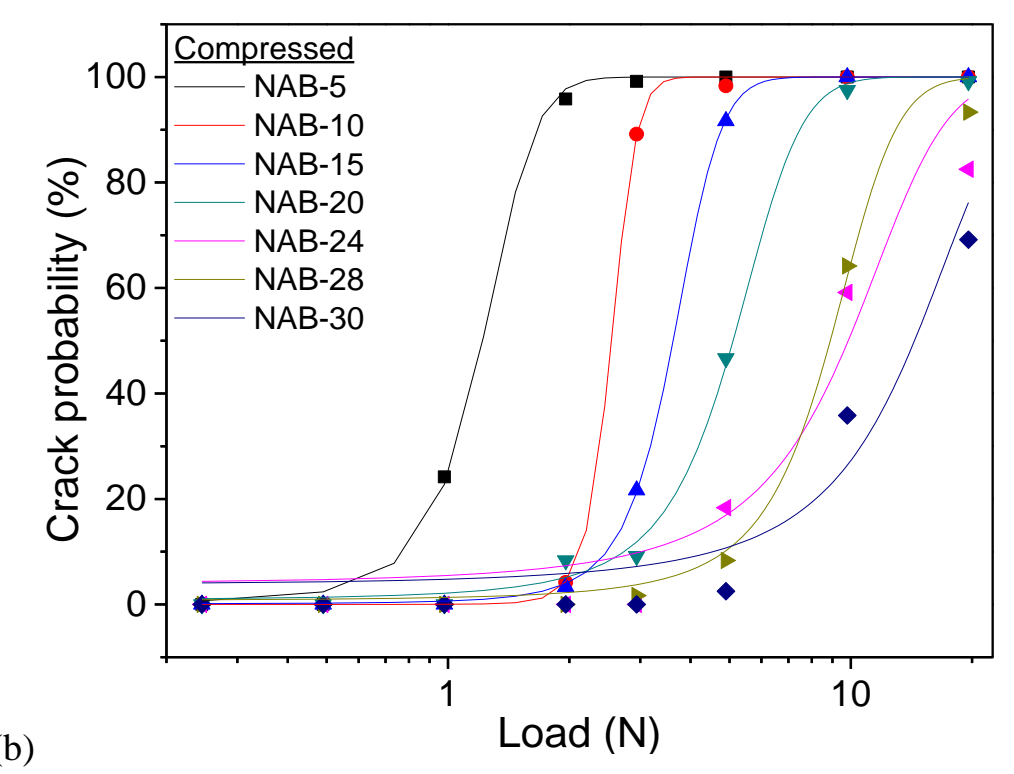


Figure 11. Composition dependence of (a) crack resistance $(C R)$ and (b) the ratio between radial crack length $(c)$ and half of the indent diagonal (a) for as-prepared and compressed sodium aluminoborate glasses. The dotted line represents the border between the peralkaline and peraluminous region. The error bars represent standard deviation of at least thirty indentations.

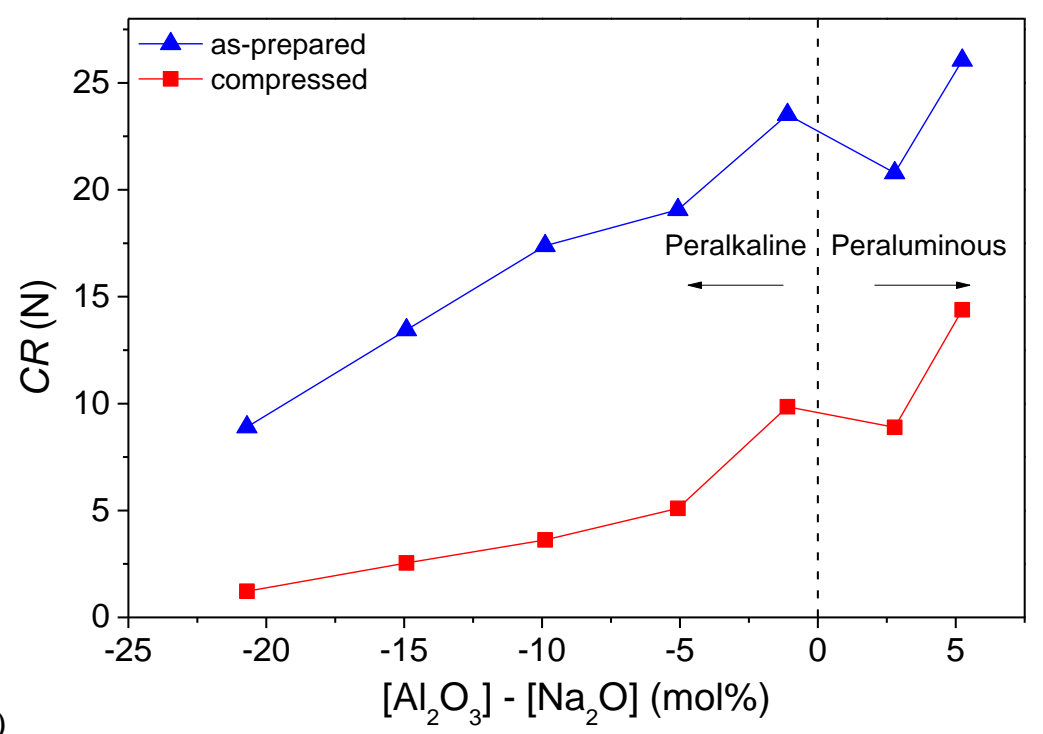

(a)

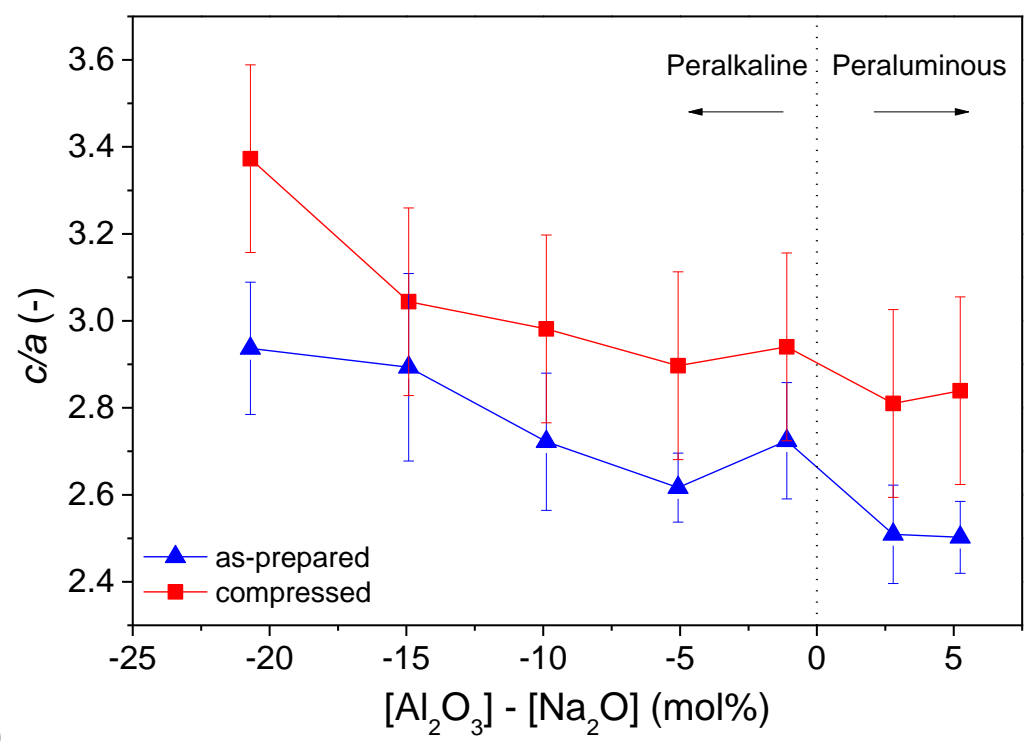


Figure 12. (a) AFM-images before (left) and after (right) a sub- $T_{g}$ annealing at $0.9 T_{g}$ for 2 hours for NAB24. (b) Composition dependence of volume recovery ratio $\left(V_{R}\right)$ and pile-up volume ratio $\left(V_{P}\right)$ for the asprepared sodium aluminoborate glasses. The dotted line represents the border between the peralkaline and peraluminous region. The error bars represent standard deviation of ten indentations.

(a)
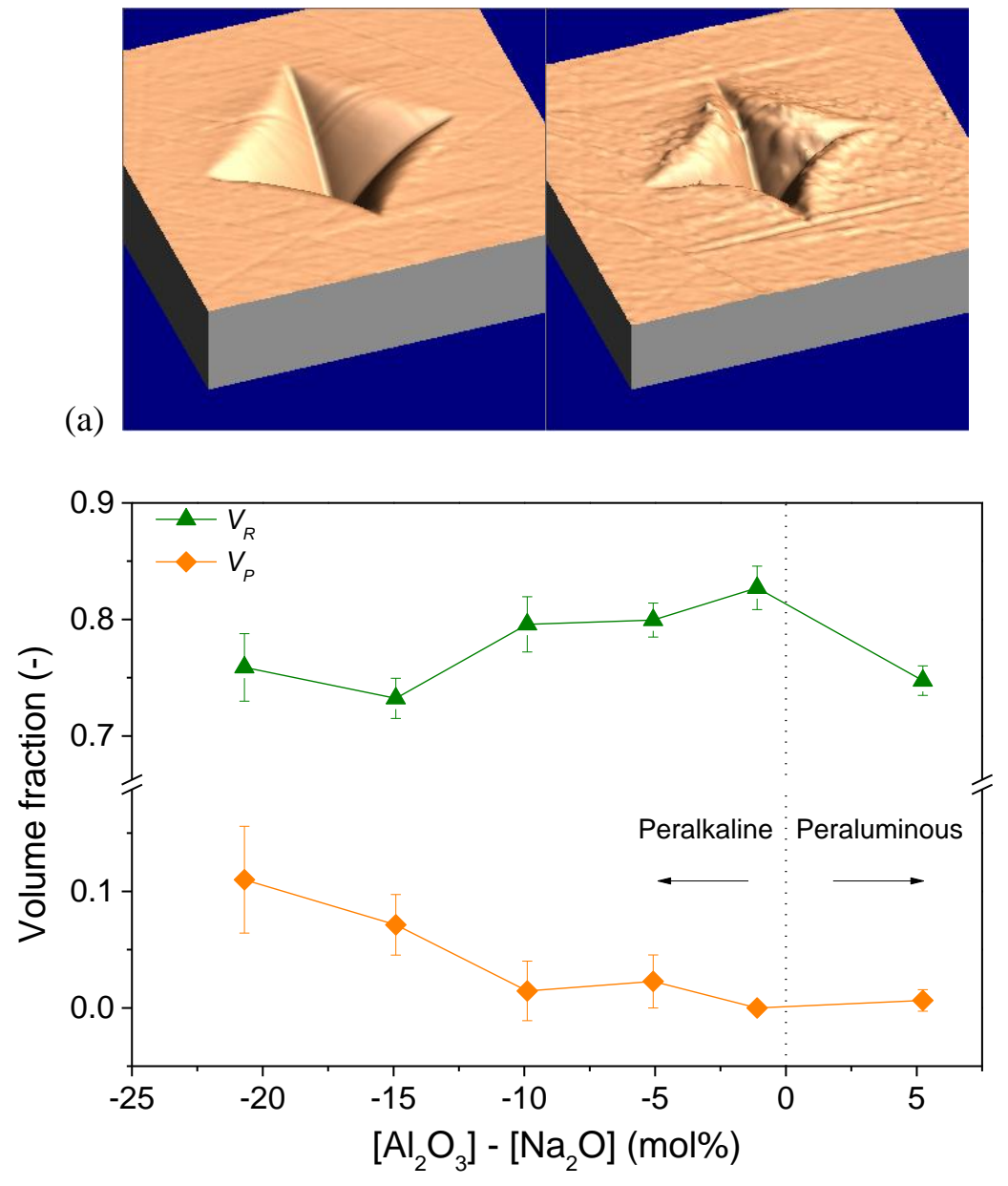

(b) 
Figure 13. Correlation between the volume recovery ratio $\left(V_{R}\right)$ and atomic packing density $\left(C_{g}\right)$ for various oxide glasses. Data are taken from Refs. $[15,17,23,51,58-61,63]$ and this work.

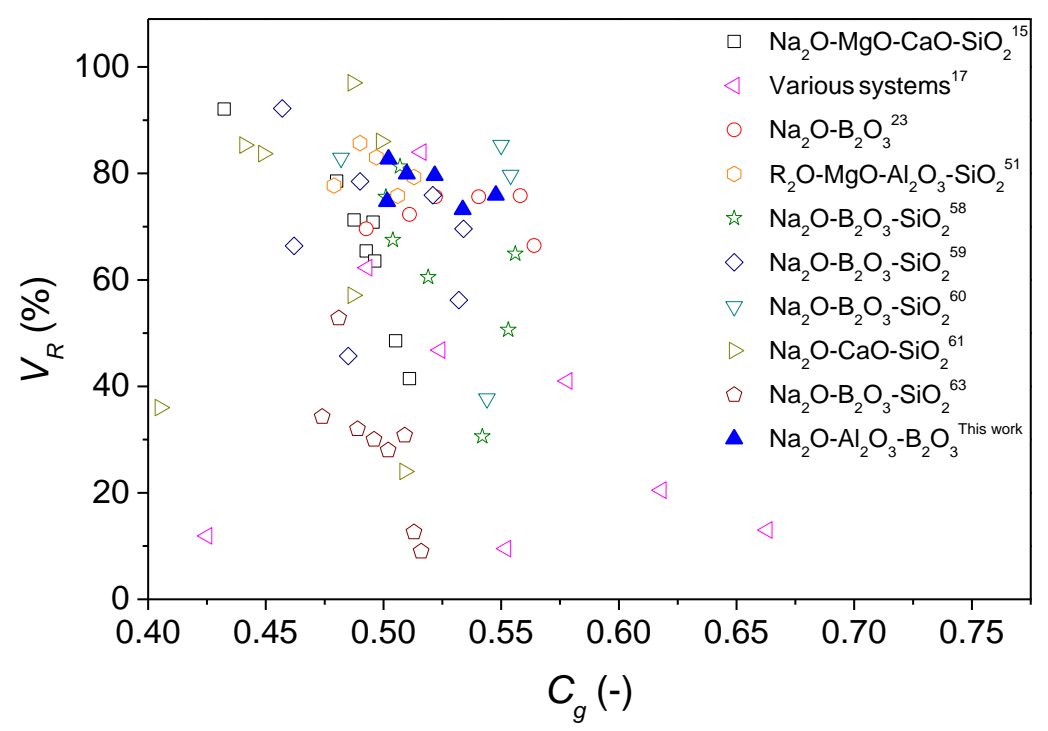


Figure 14. Correlation between crack resistance $(C R)$ and volume recovery ratio $\left(V_{R}\right.$, black squares) and plastic compressibility ( $\beta$, orange diamonds) for the as-prepared sodium aluminoborate glasses. The dashed lines represent linear fits to the data and the coefficients of determination $\left(R^{2}\right)$ are indicated.

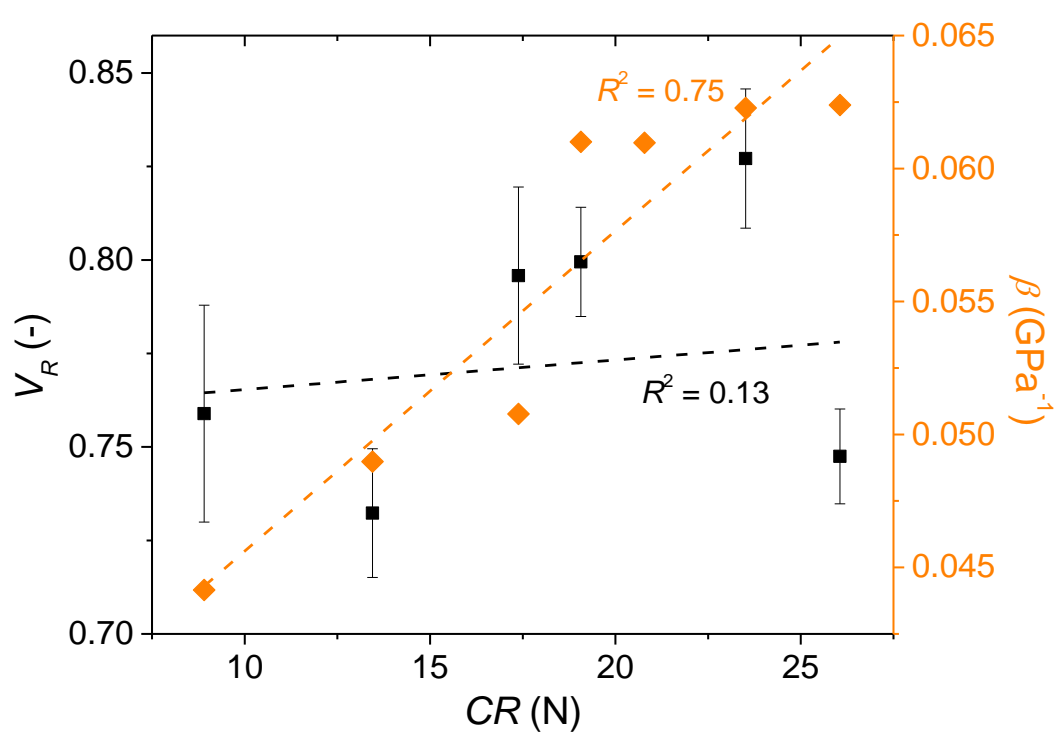

